\title{
DFT Study on the Catalytic Activity of ALD-grown Diiron Oxide Nanoclusters for Partial Oxidation of Methane to Methanol
}

\author{
Melissa Barona, ${ }^{\mathrm{a}}$ Carlo Alberto Gaggioli, ${ }^{\mathrm{b}}$ Laura Gagliardi, ${ }^{\mathrm{b}}$ and Randall Q. Snurr ${ }^{\mathrm{a}, *}$ \\ ${ }^{a}$ Department of Chemical and Biological Engineering, Northwestern University, Evanston, Illinois 60208, USA \\ ${ }^{b}$ Department of Chemistry, Chemical Theory Center, and Supercomputing Institute, University of Minnesota-Twin Cities, \\ Minneapolis, Minnesota 55455, USA \\ *corresponding author
}

\section{Supporting Information}

\section{Contents}

Section S1: Diiron oxide nanocluster growth via atomic layer deposition (ALD) Page S1

Section S2: Effect of porphyrin support on reaction energy pathway

Page S3

Section S3: Methane-to-methanol conversion pathways via $\mathrm{O}_{\mathrm{t}}$ site

Page S6

Section S4: Spin state energy ladder with different functionals

Page S8

Section S5: Multireference calculations

Page S10

Section S6: 11-et vs. nonet spin state energy surfaces

Page S24

Section S7: Modeling of the reaction at the high spin and low spin potential

Page S26

energy surfaces

Section S8: Population analysis

Page S32

Section S9: Molecular orbital analysis

Page S34

Section S10: Species DFT electronic energies

Page S36

Section S11: Full Gaussian citation

Page S37

References

Page S37

\section{Section S1}

\section{Diiron oxide nanocluster growth via atomic layer deposition (ALD)}

Atomic layer deposition (ALD) consists of an A cycle of a metal precursor and a B cycle of water vapor or other reagent to remove the ligands of the metal precursor and deposit a single metal "layer". The growth of the diiron cluster proposed in this study consists of an Al ALD cycle, an Fe ALD cycle, and an oxidation step. To demonstrate how the ALD process would occur, we use trimethyl aluminum (TMA) for the Al ALD cycle and bis(N,N'-di-tbutylacetamidinato) iron(II) for the Fe ALD cycle as example precursors (Figure S1). During the Al ALD cycle (Figure S2), the Al precursor (A Cycle) reacts with the $\mathrm{M}-\mathrm{OH}$ group of the metalated porphyrinic linker. A hydrogen transfer from the -OH promotes the removal of one of the three trimethyl ligands (Figure S2b). The system is then purged with water vapor (B cycle) to remove the rest of the ligands via hydrolysis (Figure S2d-g). The Al ALD process results in two hydroxide groups bound to the $\mathrm{Al}$ atom that can serve as nucleation sites for the deposition of iron atoms (Figure S2g and Figure S3a). This process is shown in Figure S3. In a single iron (II) ALD cycle, the resulting hydroxo groups attached to the deposited aluminum atom each react with a ligand of the Fe precursor. For clarity, we show a stepwise adsorption of one precursor on one hydroxo group (Figure S3a), followed by a hydrogen transfer and the release of one protonated ligand Figure S3b). Once a ligand is released, a second iron precursor adsorbs on the empty hydroxo group (Figure S3c), and a proton transfer promotes the release of another ligand 
(Figure S3d). This results in the formation of a bridging oxygen between the aluminum atom and each of the iron atoms, each with one ligand remaining. Water vapor is flowed over the system to remove the remaining ligands one at a time (Figure S3e-h). The bridging oxygen atoms can then be incorporated using $\mathrm{O}_{2}$ or $\mathrm{N}_{2} \mathrm{O}$ as shown in Scheme 1 in the main manuscript.<smiles>C[Al](C)C</smiles>

(a)

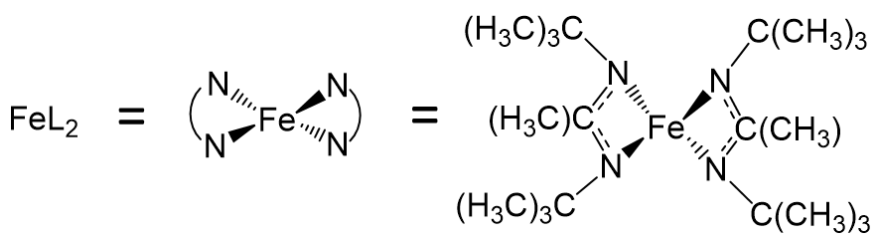

(b)

Figure S1. (a) trimethyl aluminum (III) precursor and (b) bis(N,N'-di-t-butylacetamidinato) iron(II) precursor

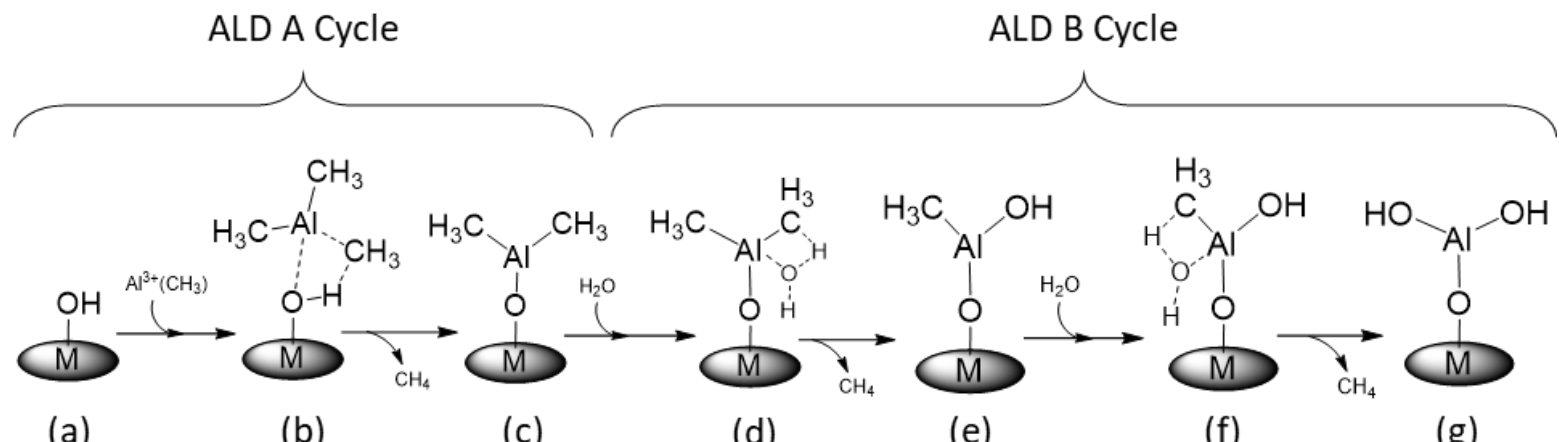

Figure S2. Proposed mechanism for the aluminum (III) ALD process. Water molecules from the $\mathrm{B}$ cycle that would coordinate to the aluminum centers are omitted for clarity.

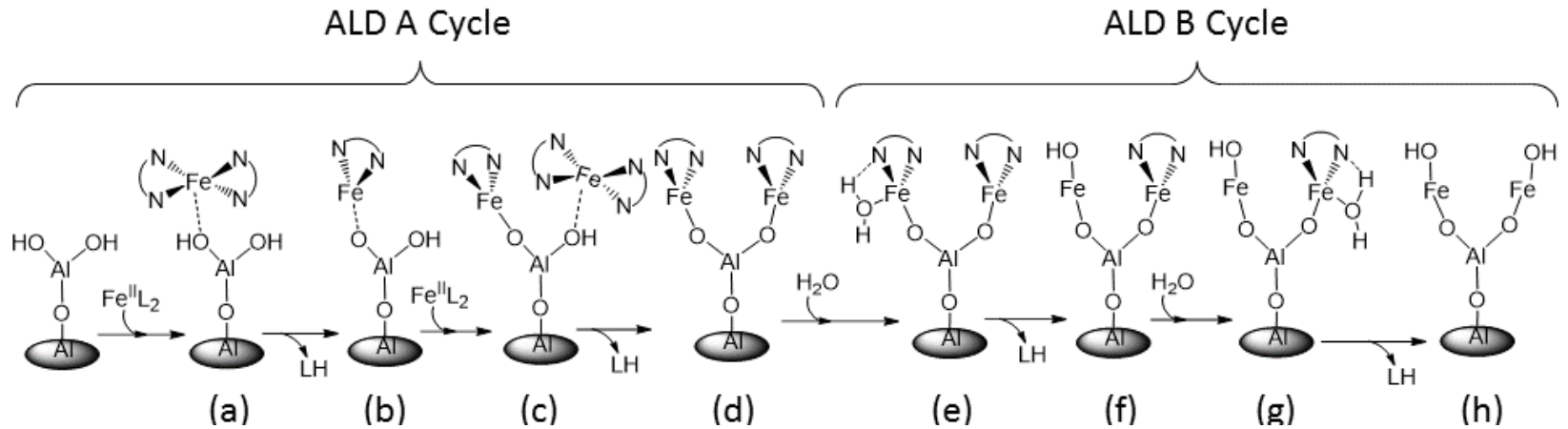

(a)

(b)

(c)

(d)

(e)

(f)

(g)

(h)

Figure S3. Proposed mechanism for the iron (II) ALD process. Water molecules from the B cycle that could coordinate to the iron and aluminum centers are omitted for clarity. 


\section{Section S2}

\section{Effect of porphyrin support on reaction energy pathway}

In this section we examine the effect of the porphyrin support on the energy pathways for the proposed methane-to-methanol conversion mechanisms via the $\mathrm{O}_{\mathrm{b}}$ site. The energy profile was calculated on two cluster models: (1) a porphyrin-supported diiron cluster and (2) a cluster model in which the porphyrin is replaced with a hydrogen atom. The model for the porphyrin support used to model the partial oxidation of methane to methanol on the diiron oxide cluster is shown in Figure S4a. It consists of an iron (III) tetrakis(carboxyphenyl)porphyrin (TCPP) linker extracted from an experimental X-ray structure of the MOF PCN-222. ${ }^{1}$ Here we use the methodology previously implemented in our group for a porphyrin-supported copper-oxide cluster, in which the $\mathrm{Fe}^{3+}-\mathrm{Cl}$ moiety of the TCPP linker is replaced with an $\mathrm{Al}^{3+}-\mathrm{OH}$ moiety. ${ }^{2}$ The empty d orbitals of $\mathrm{Al}^{3+}$ allow us to only consider the spin states associated with the iron atoms of the cluster. The four carboxyl groups at the ends of the support were protonated to make the structure neutral. The structure is allowed to relax, with the exception of the carbon and oxygen atoms at the formate ends of the support, which are kept fixed to retain the constraints placed on the porphyrin by the structure of the MOF. For the calculations using the cluster model in Figure S4b, the positions of all atoms are allowed to relax. Figure S5 shows the comparison of the reaction energetics for the conversion of methane to methanol and the regeneration of the $\mathrm{O}_{b}$ site on the porphyrin-supported cluster model and the truncated cluster model. Figure S6 shows bar plots comparing the reaction energies, forward activation energies, and reverse activation energies for each of the steps in the catalytic reaction. The two models show similar reactivity, with the largest difference in the $\mathrm{N}_{2} \mathrm{O}$ activation barrier of about $20 \mathrm{~kJ} / \mathrm{mol}$. The root mean square deviation (RMSD) for all reaction energies, forward activation energies, and reverse activation energies is $10.1 \mathrm{~kJ} / \mathrm{mol}$ and the mean average error (MAE) is $8.3 \mathrm{~kJ} / \mathrm{mol}$.

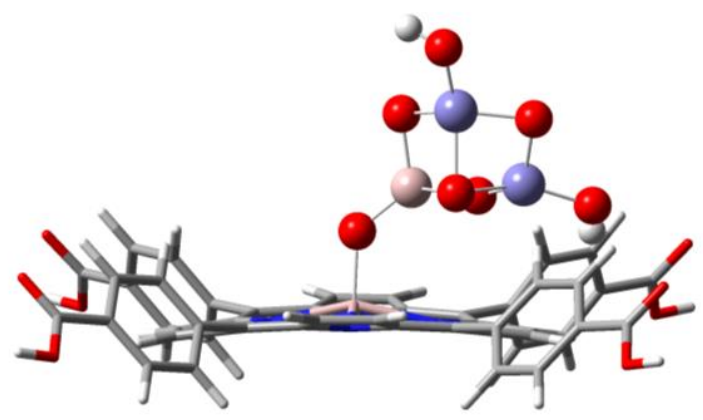

(a)

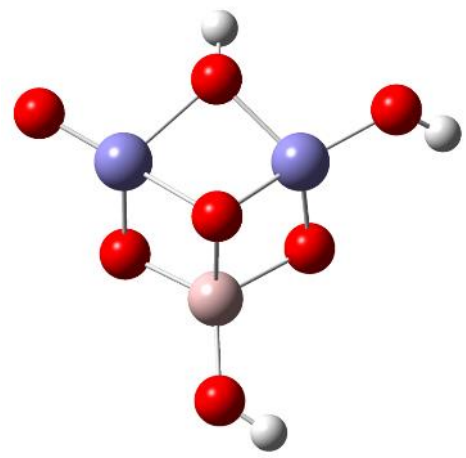

(b)

Figure S4: (a) Full model with porphyrin support and (b) truncated model. Color code: H (white), O (red), Fe (ice blue). Porphyrin: N (blue), C (gray). 


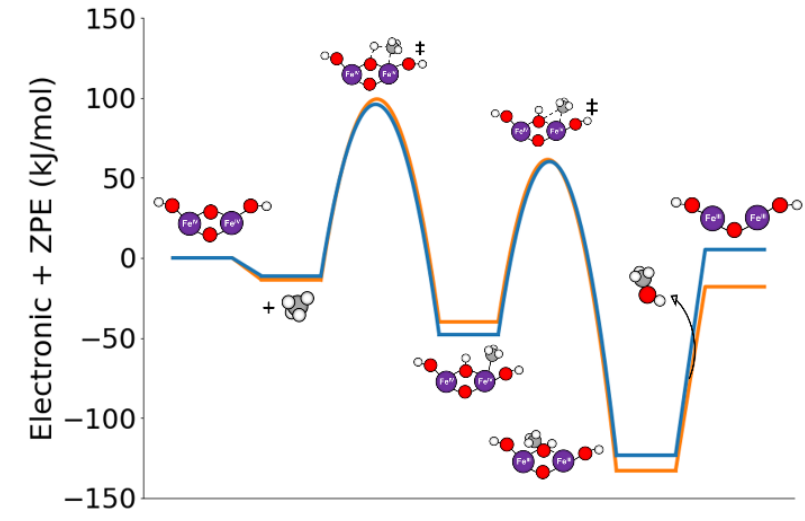

(a)

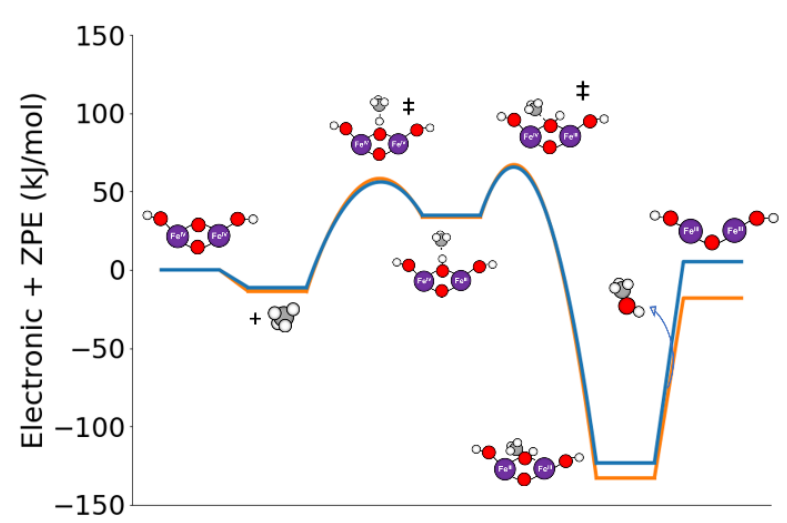

(b)

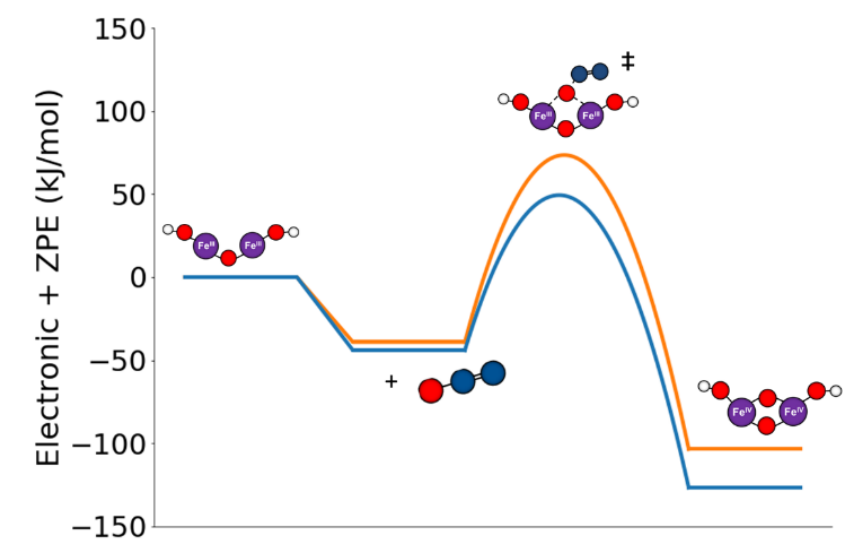

(c)

Figure S5: Comparison of energy profiles for (a) the conversion of methane to methanol via a concerted $\mathrm{C}-\mathrm{H}$ bond cleavage, (b) the conversion of methane to methanol via $\mathrm{H}$-abstraction, and (c) the $\mathrm{N}_{2} \mathrm{O}$ activation through the $\mathrm{O}_{\mathrm{b}}$ site. Orange corresponds to the diiron cluster model on the porphyrin and blue corresponds to the diiron cluster model in which the porphyrin is replaced with a hydrogen atom.

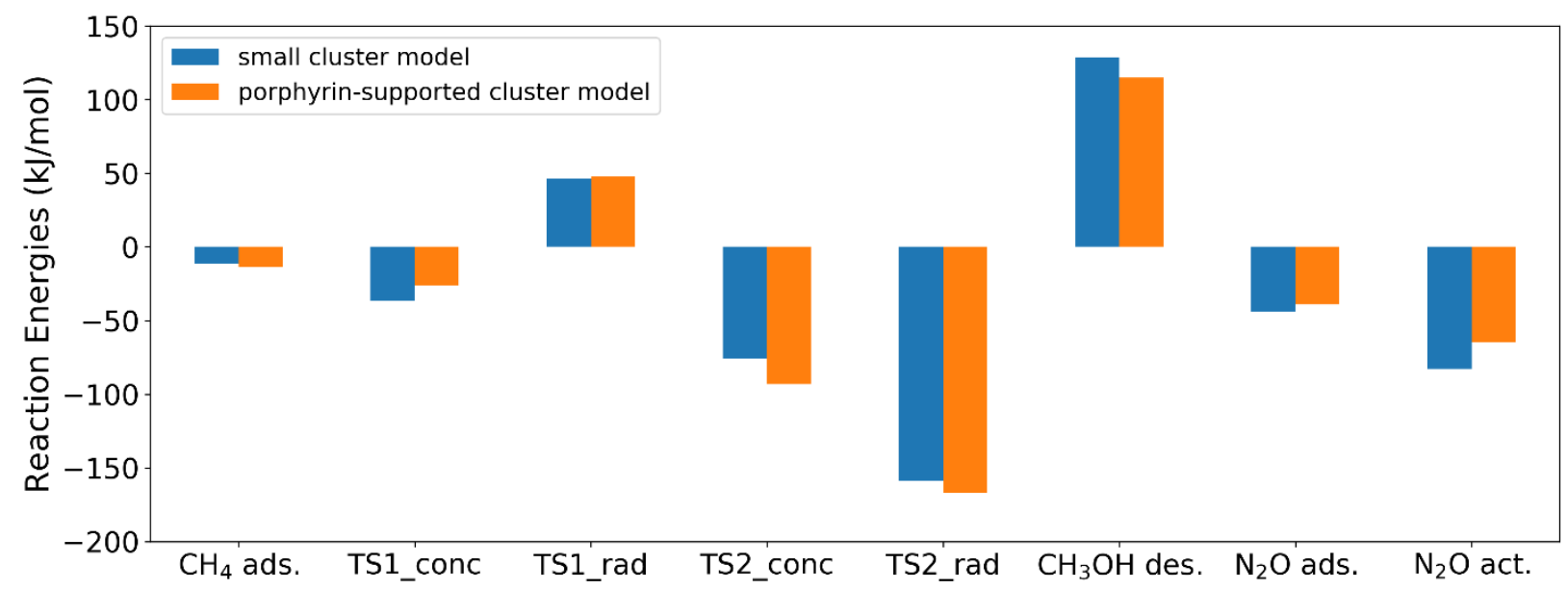

(a) 


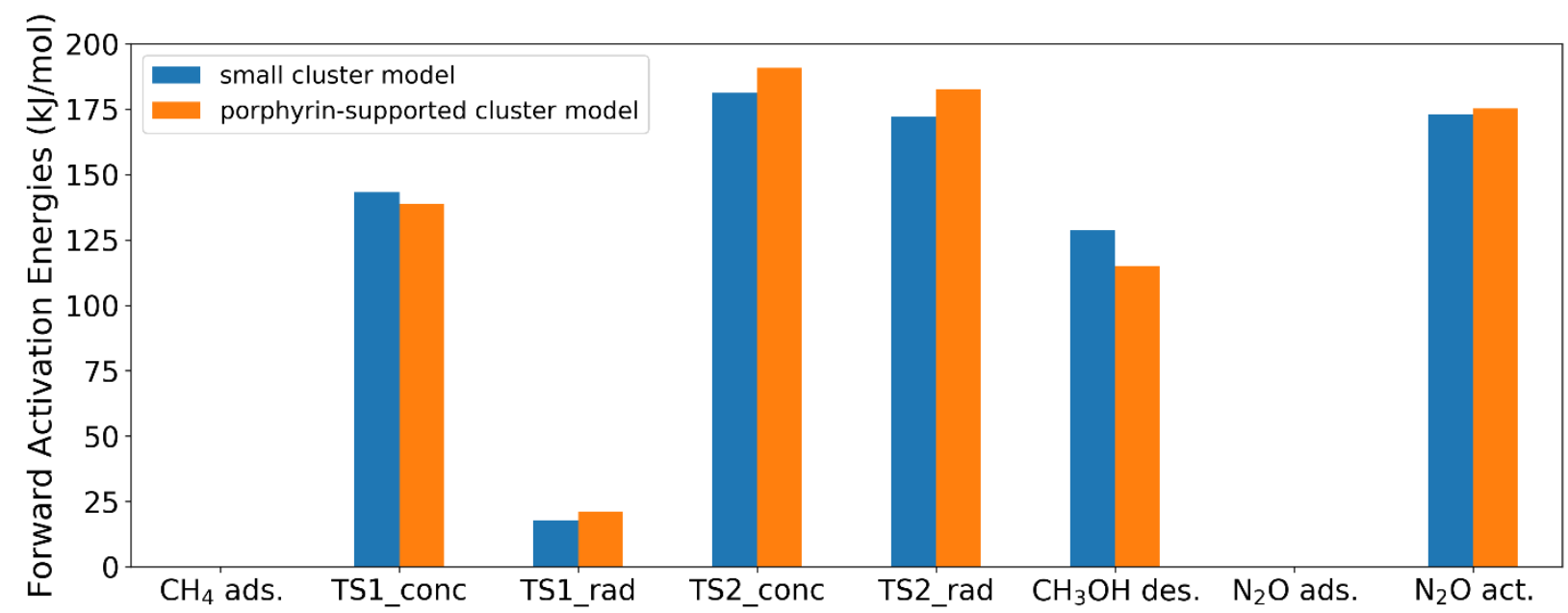

(b)

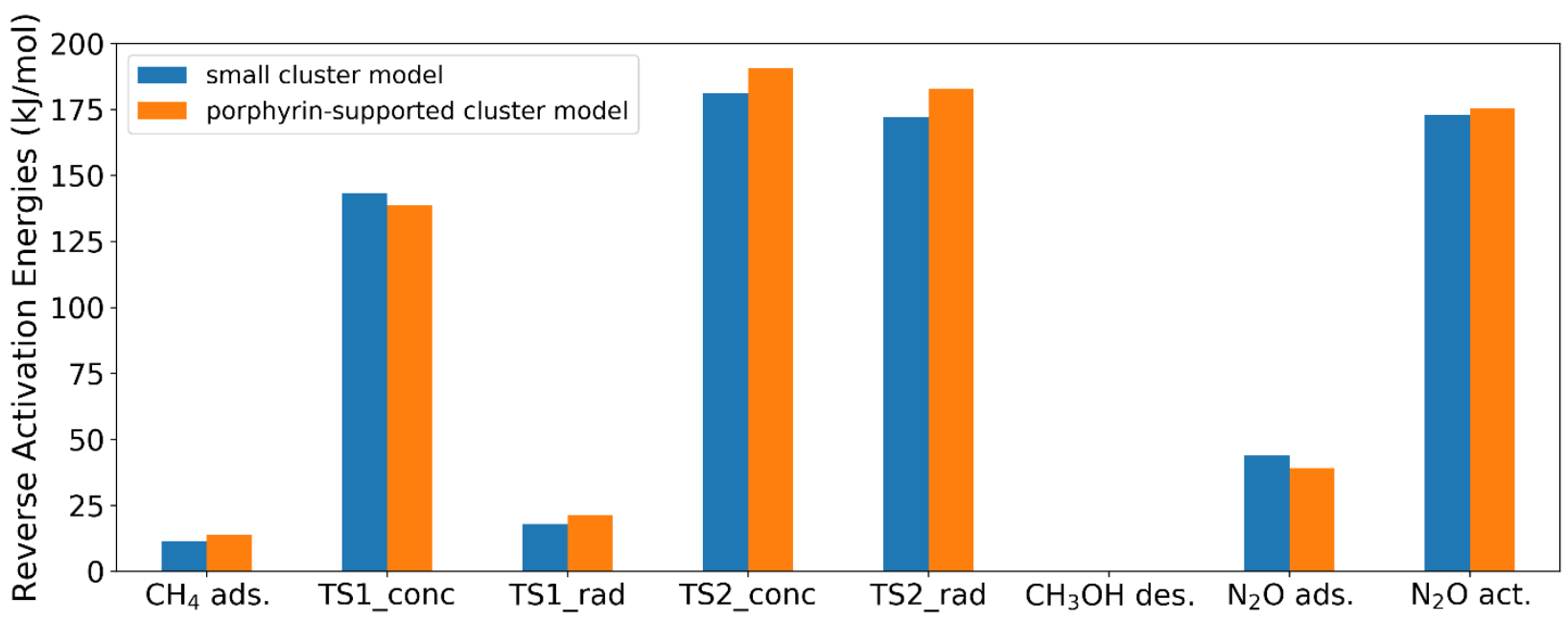

(c)

Figure S6: Comparison of the (a) reaction energies, (b) forward reaction activation energies, and (c) reverse reaction activation energies of the catalytic pathway through the $\mathrm{O}_{b}$ site. Orange corresponds to the diiron cluster model on the porphyrin and blue corresponds to the diiron cluster model in which the porphyrin is replaced with a hydrogen atom. 
Section S3

Methane-to-methanol conversion pathways via $O_{t}$ site

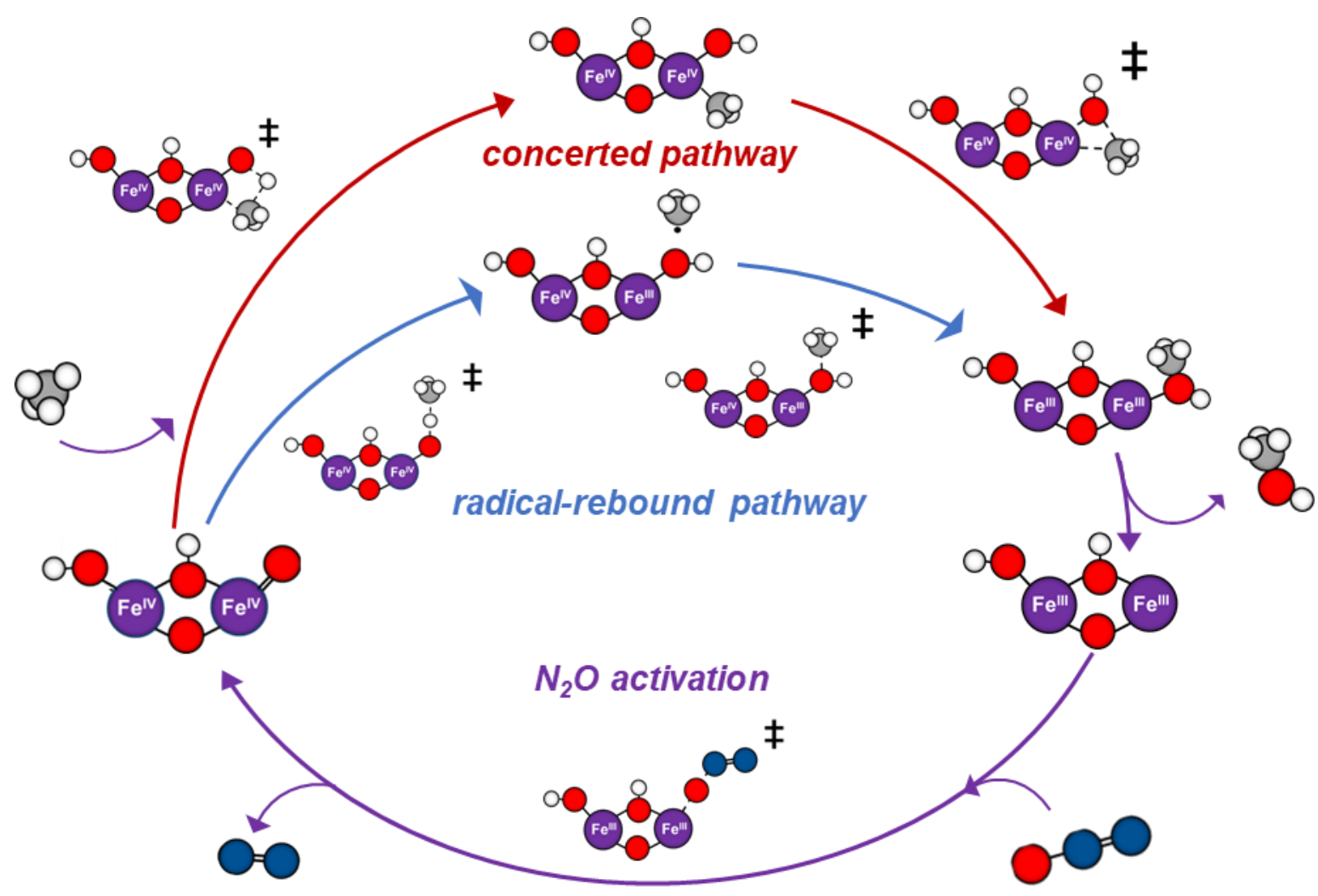

Figure S7: Proposed catalytic pathway for the oxidation of methane to methanol on the $\mathrm{O}_{\mathrm{t}}$ site, which is regenerated using $\mathrm{N}_{2} \mathrm{O}$. The concerted pathway, radical-rebound pathway, and $\mathrm{N}_{2} \mathrm{O}$ activation are represented by the red, blue, and purple lines respectively. For clarity, only the most relevant atoms of the catalytic cluster are shown, which includes the two iron metals and the two bridging oxygens and terminal -OH groups. 
Table S1: Steps for the for the conversion of methane to methanol using $\mathrm{N}_{2} \mathrm{O}$ as the oxidant. $\mathrm{O}_{t}$ refers to the terminal oxygen atom of the diiron cluster. A slash indicates a weakly bound complex. A star signifies a single catalytic species structure.

$\mathrm{CH}_{4}$ adsorption

$\mathrm{C}-\mathrm{H}$ cleavage (concerted)

$\mathrm{CH}_{3} \mathrm{OH}$ formation (concerted)

C-H cleavage (radical-rebound)

$\mathrm{CH}_{3} \mathrm{OH}$ formation (radicalrebound)

$\mathrm{CH}_{3} \mathrm{OH}$ desorption

$\mathrm{N}_{2} \mathrm{O}$ adsorption

$\mathrm{N}_{2} \mathrm{O}$ activation

$\mathrm{N}_{2}$ desorption

$$
\begin{gathered}
{\left[\mathrm{Fe}^{4+} \mathrm{Fe}^{4+} \mathrm{O}_{\mathrm{t}}\right]+\mathrm{CH}_{4} \rightarrow\left[\mathrm{Fe}^{4+} \mathrm{Fe}^{4+} \mathrm{O}_{t} / \mathrm{CH}_{4}\right]^{*}} \\
{\left[\mathrm{Fe}^{4+} \mathrm{Fe}^{4+} \mathrm{O}_{\mathrm{t}} / \mathrm{CH}_{4}\right]^{*} \rightarrow\left[\mathrm{Fe}^{4+} \mathrm{Fe}^{4+}\left(\mathrm{O}_{\mathrm{t}}-\mathrm{H}\right)\left(\mathrm{CH}_{3}\right)\right]^{*}} \\
{\left[\mathrm{Fe}^{4+} \mathrm{Fe}^{4+}\left(\mathrm{O}_{\mathrm{t}}-\mathrm{H}\right)\left(\mathrm{CH}_{3}\right)\right]^{*} \rightarrow\left[\mathrm{Fe}^{3+} \mathrm{Fe}^{3+}\left(\mathrm{CH}_{3} \mathrm{O}_{\mathrm{t}} \mathrm{H}\right)\right]^{*}} \\
{\left[\mathrm{Fe}^{4+} \mathrm{Fe}^{4+} \mathrm{O}_{\mathrm{t}} / \mathrm{CH}_{4}\right]^{*} \rightarrow\left[\mathrm{Fe}^{3+} \mathrm{Fe}^{4+}\left(\mathrm{O}_{\mathrm{t}}-\mathrm{H}\right) /{ }^{\bullet} \mathrm{CH}_{3}\right]^{*}} \\
{\left[\mathrm{Fe}^{3+} \mathrm{Fe}^{4+}\left(\mathrm{O}_{\mathrm{t}} \mathrm{H}\right) /{ }^{\bullet} \mathrm{CH}_{3}\right]^{*} \rightarrow\left[\mathrm{Fe}^{3+} \mathrm{Fe}^{3+}\left(\mathrm{CH}_{3} \mathrm{O}_{\mathrm{t}} \mathrm{H}\right)\right]^{*}} \\
{\left[\mathrm{Fe}^{3+} \mathrm{Fe}^{3+}\left(\mathrm{CH}_{3} \mathrm{O}_{\mathrm{t}} \mathrm{H}\right)\right]^{*} \rightarrow\left[\mathrm{Fe}^{3+} \mathrm{Fe}^{3+}\right]^{*}+\mathrm{CH}_{3} \mathrm{O}_{\mathrm{t}} \mathrm{H}} \\
{\left[\mathrm{Fe}^{3+} \mathrm{Fe}^{3+}\right]_{\mathrm{t}}^{*}+\mathrm{N}_{2} \mathrm{O}_{\mathrm{t}} \rightarrow\left[\mathrm{Fe}^{3+} \mathrm{Fe}^{3+} / \mathrm{N}_{2} \mathrm{O}_{\mathrm{t}}\right]^{*}} \\
{\left[\mathrm{Fe}^{3+} \mathrm{Fe}^{3+} / \mathrm{N}_{2} \mathrm{O}_{\mathrm{t}}\right]^{*} \rightarrow\left[\mathrm{Fe}^{4+} \mathrm{Fe}^{4+} \mathrm{O}_{\mathrm{t}} / \mathrm{N}_{2}\right]^{*}} \\
{\left[\mathrm{Fe}^{4+} \mathrm{Fe}^{4+} \mathrm{O}_{\mathrm{t}} / \mathrm{N}_{2}\right]^{*} \rightarrow\left[\mathrm{Fe}^{4+} \mathrm{Fe}^{4+} \mathrm{O}_{\mathrm{t}}\right]+\mathrm{N}_{2}}
\end{gathered}
$$




\section{Section S4}

\section{Spin state energy ladder with different functionals}

Table S2: Percent $S^{2}$ value deviation from expected $S^{2}$ value for the oxidized clusters $\left[\mathrm{Fe}^{4+} \mathrm{O}_{\mathrm{b}} \mathrm{Fe}^{4+}\right]$ and $\left[\mathrm{Fe}^{4+} \mathrm{Fe}^{4+} \mathrm{O}_{\mathrm{t}}\right]$ and the reduced clusters $\left[\mathrm{Fe}^{3+} \mathrm{Fe}^{3+}\right]_{\mathrm{b}}$ and $\left[\mathrm{Fe}^{3+} \mathrm{Fe}^{3+}\right]_{\mathrm{t}}$ at the M06- $\mathrm{L}$, OPBE, M06, B3LYP, PBE0 levels of theory including D3 dispersion for the following spin states: (a) triplet, (b) quintet, (c) septet, (d) nonet, and (e) 11-et. We omit a table for the openshell singlet since the expected $S^{2}$ value for a singlet is zero and dividing the $S^{2}$ value deviation by zero results in infinity.

\begin{tabular}{|c|c|c|c|c|c|}
\hline \multicolumn{7}{|c|}{ Multiplicity $=3$} \\
\hline & M06-L & OPBE & M06 & B3LYP & PBE0 \\
\hline$\left[\mathbf{F e}^{\mathbf{4 +}} \mathbf{O}_{\mathbf{b}} \mathbf{F e}^{\mathbf{4 +}}\right]$ & $149 \%$ & $137 \%$ & $14.4 \%$ & $11.5 \%$ & $52.3 \%$ \\
\hline$\left[\mathbf{F e}^{\mathbf{4}} \mathbf{F e}^{\mathbf{4 +}} \mathbf{O}_{\mathbf{t}}\right]$ & $111 \%$ & $145 \%$ & $24.1 \%$ & $49.2 \%$ & $54.0 \%$ \\
\hline$\left[\mathbf{F e}^{3+} \mathbf{F e}^{3+}\right]_{\mathbf{b}}$ & $152 \%$ & $146 \%$ & $102 \%$ & $79.7 \%$ & $92.4 \%$ \\
\hline$\left[\mathbf{F e}^{3+} \mathbf{F e}^{3+}\right]_{\mathbf{t}}$ & $155 \%$ & $148 \%$ & $159 \%$ & $154 \%$ & $88.6 \%$ \\
\hline
\end{tabular}

(a)

\begin{tabular}{|c|c|c|c|c|c|}
\hline \multicolumn{6}{|c|}{ Multiplicity $=5$} \\
\hline & M06-L & OPBE & M06 & B3LYP & PBEO \\
\hline$\left[\mathrm{Fe}^{4+} \mathrm{O}_{\mathrm{b}} \mathrm{Fe}^{4+}\right]$ & $15.1 \%$ & $1.31 \%$ & $5.03 \%$ & $2.37 \%$ & $3.39 \%$ \\
\hline$\left[\mathrm{Fe}^{4+} \mathrm{Fe}^{4+} \mathrm{O}_{\mathrm{t}}\right]$ & $16.8 \%$ & $3.20 \%$ & $4.03 \%$ & $2.23 \%$ & $8.54 \%$ \\
\hline$\left[\mathrm{Fe}^{3+} \mathrm{Fe}^{3+}\right]_{\mathrm{b}}$ & $27.6 \%$ & $25.0 \%$ & $18.8 \%$ & $14.0 \%$ & $18.4 \%$ \\
\hline$\left[\mathrm{Fe}^{3+} \mathrm{Fe}^{3+}\right]_{t}$ & $25.0 \%$ & $25.0 \%$ & $7.58 \%$ & $9.74 \%$ & $12.2 \%$ \\
\hline
\end{tabular}

(b)

\begin{tabular}{|c|c|c|c|c|c|}
\hline \multicolumn{6}{|c|}{ Multiplicity $=7$} \\
\hline & M06-L & OPBE & M06 & B3LYP & PBEO \\
\hline$\left[\mathrm{Fe}^{4+} \mathrm{O}_{\mathrm{b}} \mathrm{Fe}^{4+}\right]$ & $1.43 \%$ & $0.81 \%$ & $2.05 \%$ & $1.17 \%$ & $1.33 \%$ \\
\hline$\left[\mathrm{Fe}^{4+} \mathrm{Fe}^{4+} \mathrm{O}_{\mathrm{t}}\right]$ & $0.35 \%$ & $0.74 \%$ & $2.66 \%$ & $1.21 \%$ & $1.64 \%$ \\
\hline$\left[\mathrm{Fe}^{3+} \mathrm{Fe}^{3+}\right]_{\mathrm{b}}$ & $1.56 \%$ & $1.02 \%$ & $2.40 \%$ & $1.00 \%$ & $1.20 \%$ \\
\hline$\left[\mathrm{Fe}^{3+} \mathrm{Fe}^{3+}\right]_{t}$ & $4.78 \%$ & $1.07 \%$ & $2.30 \%$ & $1.14 \%$ & $1.46 \%$ \\
\hline
\end{tabular}

(c)

\begin{tabular}{|c|c|c|c|c|c|}
\hline \multicolumn{6}{|c|}{ Multiplicity $=9$} \\
\hline & M06-L & OPBE & M06 & B3LYP & PBE0 \\
\hline$\left[\mathrm{Fe}^{4+} \mathrm{O}_{\mathrm{b}} \mathrm{Fe}^{4+}\right]$ & $0.83 \%$ & $0.47 \%$ & $1.17 \%$ & $0.57 \%$ & $0.73 \%$ \\
\hline$\left[\mathrm{Fe}^{4+} \mathrm{Fe}^{4+} \mathrm{O}_{\mathrm{t}}\right]$ & $0.88 \%$ & $0.44 \%$ & $1.44 \%$ & $0.65 \%$ & $0.86 \%$ \\
\hline$\left[\mathrm{Fe}^{3+} \mathrm{Fe}^{3+}\right]_{\mathrm{b}}$ & $0.66 \%$ & $0.36 \%$ & $1.73 \%$ & $0.75 \%$ & $0.92 \%$ \\
\hline$\left[\mathrm{Fe}^{3+} \mathrm{Fe}^{3+}\right]_{\mathrm{t}}$ & $0.61 \%$ & $0.30 \%$ & $0.95 \%$ & $0.45 \%$ & $0.60 \%$ \\
\hline
\end{tabular}

(d)

\begin{tabular}{|c|c|c|c|c|c|}
\hline \multicolumn{7}{|c|}{ Multiplicity $=11$} \\
\hline & M06-L & OPBE & M06 & B3LYP & PBE0 \\
\hline$\left[\mathbf{F e}^{3+} \mathbf{F e}^{3+}\right]_{\mathbf{b}}$ & $0.09 \%$ & $0.056 \%$ & $0.11 \%$ & $0.09 \%$ & $0.09 \%$ \\
\hline$\left[\mathbf{F e}^{3+} \mathbf{F e}^{3+}\right]_{\mathbf{t}}$ & $0.10 \%$ & $0.06 \%$ & $0.12 \%$ & $0.10 \%$ & $0.10 \%$ \\
\hline
\end{tabular}

(e) 


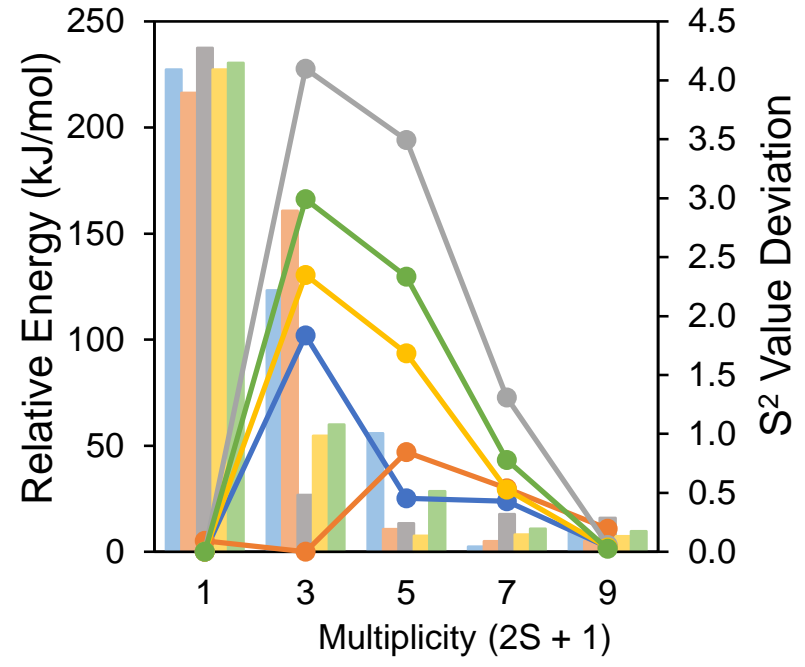

$\square$ M06-L OPBE $\backsim$ M06 $\backsim$ B3LYP $\backsim$ PBE0

(a)

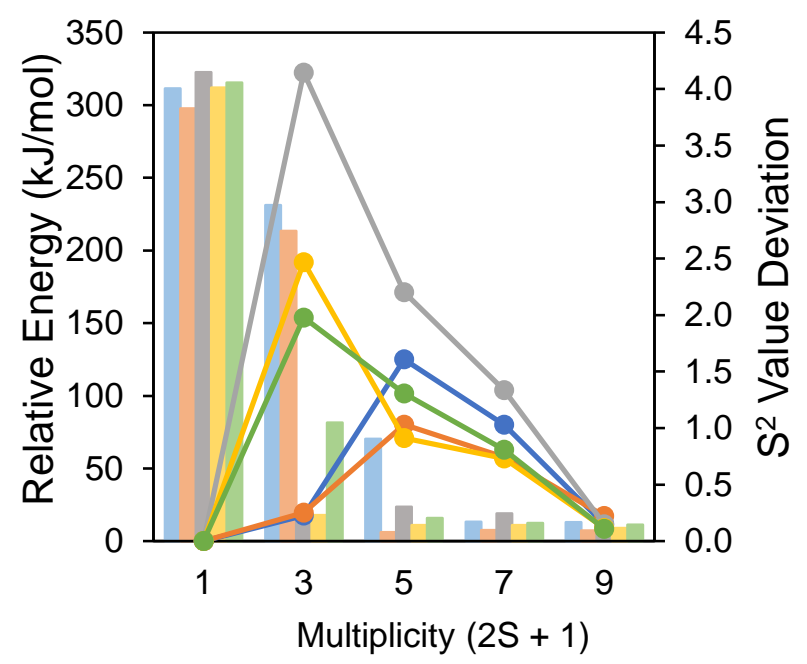

$\backsim$ M06-L $₫$ OPBE $\backsim$ M06 $₫$ B3LYP $₫$ PBE0

(c)

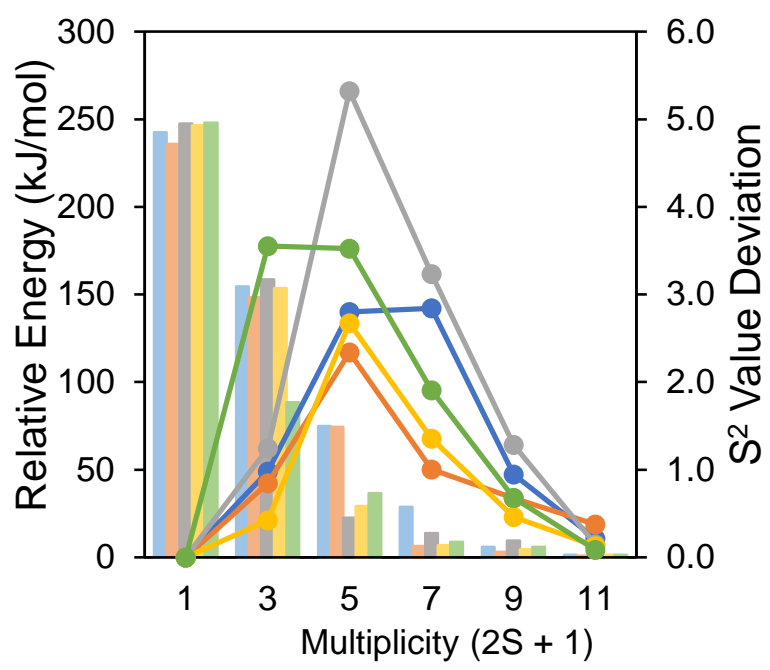

$\square$ M06-L $₫$ OPBE $\square$ M06 $₫$ B3LYP $₫$ PBE0

(b)

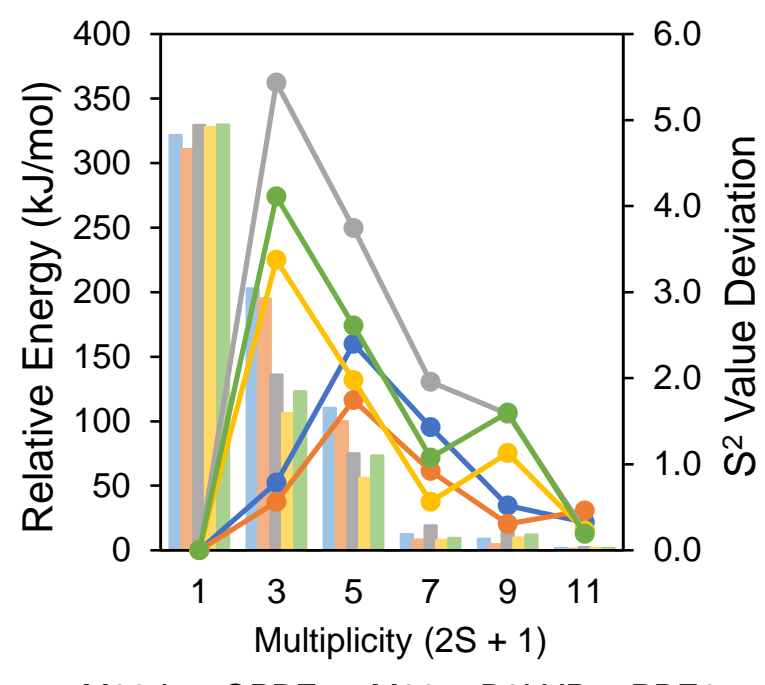

$\square$ M06-L $₫$ OPBE $\square$ M06 $₫$ B3LYP $₫$ PBE0

(d)

Figure S8: Spin ordering of all attainable spin states for the species (a) $\left[\mathrm{Fe}^{4+} \mathrm{O}_{\mathrm{b}} \mathrm{Fe}^{4+}\right]$, (b) $\left[\mathrm{Fe}^{4+} \mathrm{Fe}^{4+} \mathrm{O}_{\mathrm{t}}\right]$, (c) $\left[\mathrm{Fe}^{3+} \mathrm{Fe}^{3+}\right]_{\mathrm{b}}$, and (d) $\left[\mathrm{Fe}^{3+} \mathrm{Fe}^{3+}\right]_{\mathrm{t}}$. The lines and points correspond to the relative energies, and the bars correspond to the $\mathrm{S}^{2}$ value deviation for each spin state calculation. 


\section{Section S5}

\section{Multireference calculations}

\section{Background}

The single-determinantal nature of unrestricted Kohn-Sham (UKS) DFT refers to the use of a single wavefunction to describe a system. This wavefunction is a linear combination of the system's occupied beta and alpha molecular orbitals. Although UKS DFT accounts for spinpolarization effects that allow us to study the spin distribution in open-shell systems, the resulting wavefunction for a particular spin state of the system can be contaminated by higher spin states due to the different treatment of alpha and beta electrons. The highest possible spin states usually exhibit minimal spin contamination as there are no higher spin states from which they can become contaminated, but intermediate spin states and low spin states exhibiting antiferromagnetic coupling can become contaminated by higher spin states. A high deviation from the expected $S^{2}$ value usually indicates that the wavefunction obtained from the singledeterminantal approach in HF or DFT is not an appropriate representation of the system, and spin density values obtained from the analysis can become compromised.

In this work, we observed the highest spin states (the 11-et and nonet states for the reduced and oxidized forms of the clusters, respectively) and the open-shell singlet to be the lowest in energy compared to the intermediate states at the M06-L, M06, PBE0, B3LYP, and OPBE levels of theory (Figure S8). This agrees with the DFT study conducted by Huang and co-workers, ${ }^{3}$ in which they investigated the activity of a diiron model of sMMO for methane hydroxylation and found intermediate states to be higher in energy than the ferromagnetic and antiferromagnetic states. Because the open-shell singlet exhibits an $\mathrm{S}^{2}$ value deviations of up to 5 and intermediate spin states exhibit a percent $\mathrm{S}^{2}$ value deviation of up to $160 \%$ (Table $\mathrm{S} 2$ ) due to the unrestricted wavefunction not being an eigenfunction of the expectation value of $\hat{\mathrm{S}}^{2}$, we decided to further investigate the spin state energy ladder for the diiron clusters studied in this work using multireference methods, which we further discuss in this section. We also note that although deviation from the expected $S^{2}$ value has been used as a metric for spin contamination in $\mathrm{HF}$ and DFT, a number of studies have argued that this may be an incorrect approach for determining spin contamination in DFT results as the wavefunction from which the $\mathrm{S}^{2}$ value is calculated is that of a non-interacting system. ${ }^{4-6}$

An alternative approach to describing open-shell systems is to use multireference methods that capture the multiconfigurational character of transition metals with nearly degenerate d-orbitals. Their multiconfigurational character refers to the concept that equally good wavefunctions can describe the system by allowing electrons to occupy other nearly degenerate orbitals. The contribution that is considered from other possible wavefunctions in multireference calculations is referred to as "non-dynamical correlation," which is the "static" electron correlation that results from considering all possible configurations and arrangements that electrons can attain in a set of molecular orbitals. ${ }^{7-8}$

In a $\operatorname{CASSCF}^{9}$ (complete active space self-consistent field) multireference calculation, a full configuration interaction (full CI) expansion is performed by including all Slater determinants 
for all possible excited configurations within a selected active space of orbitals in the multiconfigurational wave function. The active space for a CASSCF calculation is represented by the notation CAS $(n, m)$, where $n$ is the total number of electrons and $m$ is the number of orbitals considered for the CI expansion. In this work, the orbitals considered for the CASSCF calculations correspond to the d-orbitals located on the iron atoms. To determine whether oxygen p orbitals are relevant for describing the system while conserving computational cost, we performed RASSCF ${ }^{10-11}$ (restricted active space self-consistent field) calculations. In RASSCF, three individual orbital subspaces are considered: RAS1, RAS2, and RAS3. RAS2 includes the d-orbitals located on the iron atoms of the cluster, RAS1 includes the doubly occupied orbitals located on the oxygen atom, and RAS3 includes unoccupied orbitals. The number of unoccupied orbitals in RAS3 is equal to the sum of the orbitals included in RAS1 and RAS2. Compared to a CASSCF calculation, RASSCF is restricted in the sense that a maximum number of electron holes are allowed in RAS1 from exciting an electron to RAS2 and RAS3, and a maximum number of excited electrons from both RAS1 and RAS2 are allowed into the unoccupied orbitals of RAS3. A full CI expansion is then performed in RAS2 as in the CAS calculation. We represent the active space for the RASSCF calculations with the notation $\operatorname{RAS}\left(n_{a e}\right.$ in $\left.n_{a o}\right) /\left(n_{a e}\right.$ in $\left.\mathrm{n}_{\mathrm{ao}}\right) / \mathrm{n}$, where $\mathrm{n}_{\mathrm{ae}}$ is the total number of active electrons in both singly and occupied orbitals in RAS1 and RAS2, $\mathrm{n}_{\mathrm{ao}}$ is the sum of active orbitals in RAS1, RAS2, and RAS3, $\mathrm{n}_{\mathrm{ae} 2}$ and $\mathrm{n}_{\mathrm{ao} 2}$ correspond to the number of electrons and orbitals in RAS2, and $n$ indicates the maximum number of electrons excited from RAS1 or into RAS3 ( $n=2$ in this case). The CASSCF/RASSCF calculations were then followed by CASPT $2^{12}$ and RASPT2 ${ }^{10,13}$ calculations on top of CASSCF/RASSCF wavefunctions, which account for the dynamic correlation of electrons using second-order perturbation theory.

\section{Computational details}

The electronic structures of oxidized clusters $\left[\mathrm{Fe}^{4+} \mathrm{O}_{\mathrm{b}} \mathrm{Fe}^{4+}\right]$ and $\left[\mathrm{Fe}^{4+} \mathrm{Fe}^{4+} \mathrm{O}_{\mathrm{t}}\right]$ and reduced clusters $\left[\mathrm{Fe}^{3+} \mathrm{Fe}^{3+}\right]_{\mathrm{b}}$ and $\left[\mathrm{Fe}^{3+} \mathrm{Fe}^{3+}\right]_{\mathrm{t}}$ were characterized using $\mathrm{CASSCF}^{9}$ and $\mathrm{RASSCF}^{10-11}$ levels of theory, followed by CASPT2 $2^{12} /$ RASPT $2^{10,13}$ calculations to assess their multiconfigurational character. All multireference (MR) calculations were performed with the MOLCAS-8.2 package $^{14}$ using the M06-L optimized geometries. The ANO-RCC-VDZP ${ }^{15}$ basis set was used for $\mathrm{H}, \mathrm{O}$, and $\mathrm{Al}$ atoms and $\mathrm{ANO}-\mathrm{RCC}-\mathrm{VTZP}^{16}$ basis set was used for $\mathrm{Fe}$ atoms. CASPT2/RASPT2 calculations were done with an IPEA shift of 0.25 and an imaginary shift of 0.2 .

\section{Examination and selection of different active spaces}

The active spaces for the CASSCF calculations were chosen by first running a single point Hartree-Fock (HF) calculation of the M06-L optimized geometries for each of the clusters at their highest spin multiplicity. The chosen orbitals located on the iron atoms were then optimized at the CASSCF level of theory for the highest multiplicity of the cluster. Figures S9-S12 show these orbitals for the oxidized clusters $\left[\mathrm{Fe}^{4+} \mathrm{O}_{\mathrm{b}} \mathrm{Fe}^{4+}\right]$ and $\left[\mathrm{Fe}^{4+} \mathrm{Fe}^{4+} \mathrm{O}_{\mathrm{t}}\right]$ and reduced clusters $\left[\mathrm{Fe}^{3+} \mathrm{Fe}^{3+}\right]_{\mathrm{b}}$ and $\left[\mathrm{Fe}^{3+} \mathrm{Fe}^{3+}\right]_{\mathrm{t}}$. All the multireference calculations consist of CASSCF and CASPT2 using the orbitals from the initial CASSCF calculation for all possible spin states. These results are shown in Tables S3-S6. For all spin states and all clusters, the active orbitals have an electron 
occupation between 0.95 and 1.05. For $\left[\mathrm{Fe}^{4+} \mathrm{O}_{\mathrm{b}} \mathrm{Fe}^{4+}\right]$ and $\left[\mathrm{Fe}^{4+} \mathrm{Fe}^{4+} \mathrm{O}_{\mathrm{t}}\right]$, delocalization of $\mathrm{Fe} \mathrm{d}$ orbitals onto $\mathrm{O}_{b}$ and $\mathrm{O}_{\mathrm{t}}$ is evident.

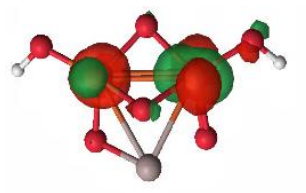

a.

(a)

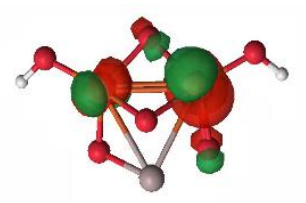

a.

(e)

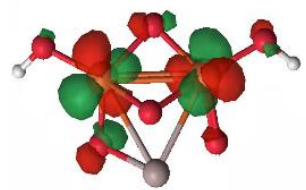

a

(b)

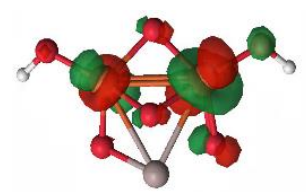

a

(f)

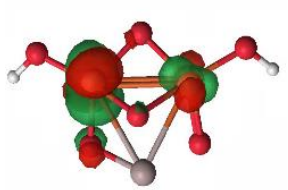

a.

(c)

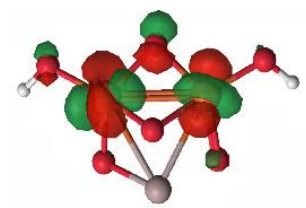

a

(g)

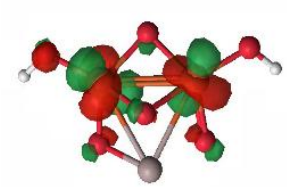

a.

(d)

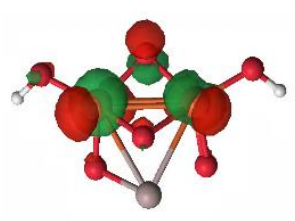

a.

(h)

Figure S9: Optimized orbitals from the $\operatorname{CASSCF}(8,8)$ calculation for $\left[\mathrm{Fe}^{4+} \mathrm{O}_{\mathrm{b}} \mathrm{Fe}^{4+}\right]$ for the nonet spin state.

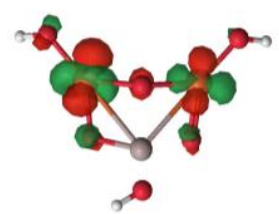

(a)

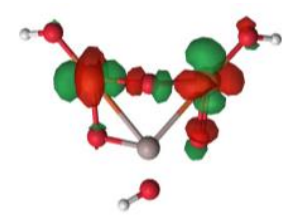

(f)

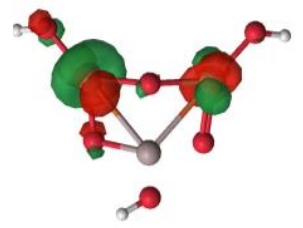

(b)

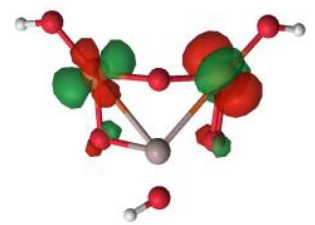

(g)

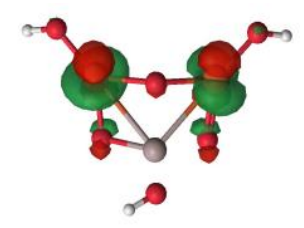

(c)

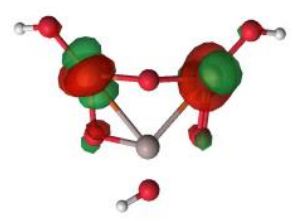

(h)

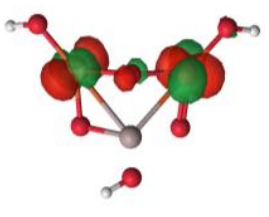

(d)

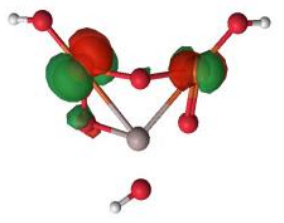

(i)

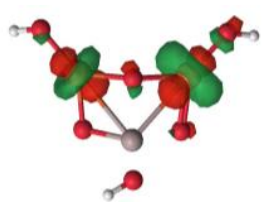

(e)

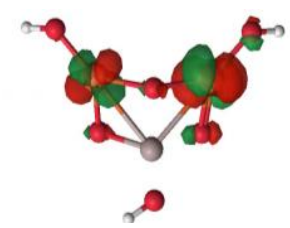

(j)

Figure S10: Optimized orbitals from the $\operatorname{CASSCF}(10,10)$ calculation for $\left[\mathrm{Fe}^{3+} \mathrm{Fe}^{3+}\right]_{\mathrm{b}}$ for the $11-$ et spin state. 


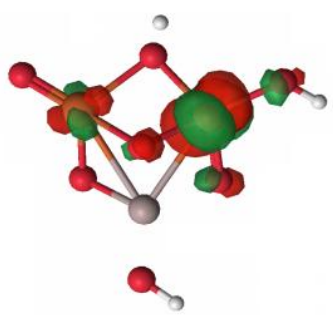

(a)

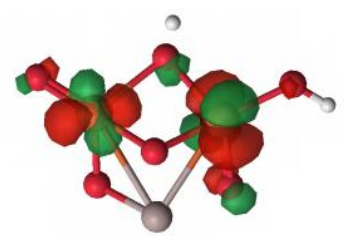

$a$

(e)

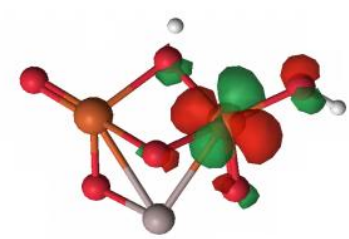

$a$

(b)

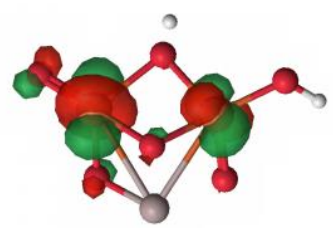

$a$

(f)

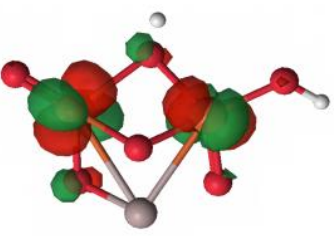

$a$

(c)

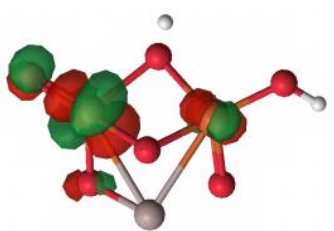

$a$

(g)

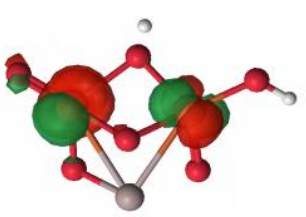

$a$

(d)

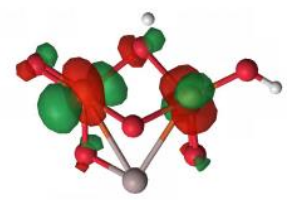

a

(h)

Figure S11: Optimized orbitals from the $\operatorname{CASSCF}(8,8)$ calculation for $\left[\mathrm{Fe}^{4+} \mathrm{Fe}^{4+} \mathrm{O}_{\mathrm{t}}\right]$ for the nonet spin state.

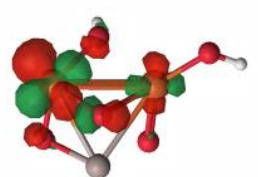

a.

(a)

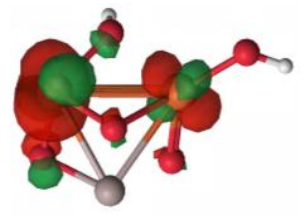

Q.

(f)

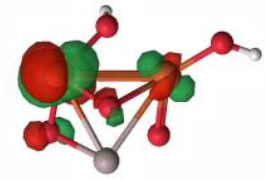

Q.

(b)

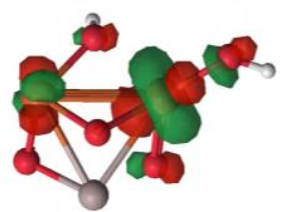

Q.

(g)

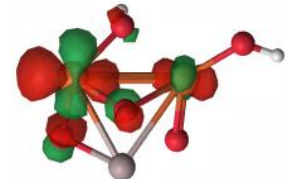

a

(c)

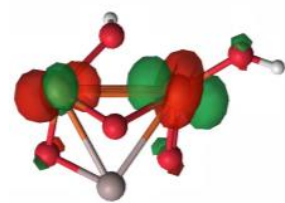

Q.

(h)

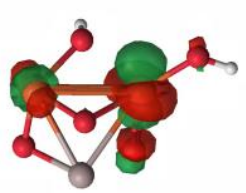

a

(d)

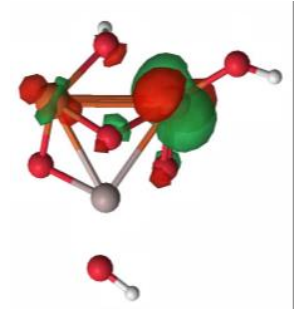

(i)

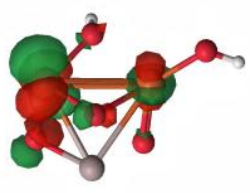

a.

(e)

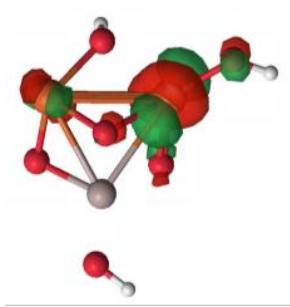

(j)

Figure S12: Optimized orbitals from the CASSCF $(10,10)$ calculation for $\left[\mathrm{Fe}^{3+} \mathrm{Fe}^{3+}\right]_{\mathrm{t}}$ for the 11et spin state. 
Our CASSCF/CASPT2 results show that all lower spin states for the four diiron species are highly multiconfigurational as they exhibit a percentage of the dominant configuration of no more than $15 \%$. There only exists one configuration for the nonet and 11-et states of the oxidized and reduced states of the clusters, respectively, corresponding to the ferromagnetic coupling of electrons between the irons, such that the percent dominant configuration is $100 \%$. The inclusion of electron dynamic correlation in CASPT2 widens the spin state energy ladder obtained from CASSCF. Our CASPT2 results show that the singlet state is the lowest in energy for all clusters except $\left[\mathrm{Fe}^{4+} \mathrm{Fe}^{4+} \mathrm{O}_{\mathrm{t}}\right]$, and between $6-33 \mathrm{~kJ} / \mathrm{mol}$ lower in energy than the highest spin states. The relative energies for the intermediate spin states lie between the singlet and highest possible spin state (nonet for the oxidized cluster, 11-et for the reduced cluster), with the exception of $\left[\mathrm{Fe}^{4+} \mathrm{Fe}^{4+} \mathrm{O}_{\mathrm{t}}\right]$, for which the septet state is only $0.65 \mathrm{~kJ} / \mathrm{mol}$ higher in energy than the nonet state.

Table S3: CASSCF and CASPT2 relative energies (in $\mathrm{kJ} / \mathrm{mol}$ ), CASPT2 reference weight, and percent contribution to the wavefunction of the most dominant configuration for $\left[\mathrm{Fe}^{4+} \mathrm{O}_{\mathrm{b}} \mathrm{Fe}^{4+}\right]$.

\begin{tabular}{|c|c|c|c|c|}
\hline & $\begin{array}{c}\text { CASSCF(8,8) } \\
\text { Energy (kJ/mol) }\end{array}$ & $\begin{array}{c}\text { CASPT2(8,8) } \\
\text { Energy (kJ/mol) }\end{array}$ & $\begin{array}{c}\text { CASPT2 } \\
\text { Reference } \\
\text { Weight }\end{array}$ & $\begin{array}{c}\text { \% Dominant } \\
\text { Configuration }\end{array}$ \\
\hline nonet & 1.22 & 32.94 & 0.534 & $100 \%$ \\
\hline septet & 1.19 & 25.28 & 0.532 & $14 \%$ \\
\hline quintet & 0.77 & 15.74 & 0.530 & $4.6 \%$ \\
\hline triplet & 0.30 & 6.77 & 0.528 & $2.7 \%$ \\
\hline singlet & 0 & 0 & 0.527 & $2.7 \%$ \\
\hline
\end{tabular}

Table S4: CASSCF and CASPT2 relative energies (in $\mathrm{kJ} / \mathrm{mol}$ ), CASPT2 reference weight, and percent contribution to the wavefunction of the most dominant configuration for $\left[\mathrm{Fe}^{3+} \mathrm{Fe}^{3+}\right]_{b}$.

\begin{tabular}{|c|c|c|c|c|}
\hline & $\begin{array}{c}\text { CASSCF(10,10) } \\
\text { Energy (kJ/mol) }\end{array}$ & $\begin{array}{c}\text { CASPT2(10,10) } \\
\text { Energy (kJ/mol) }\end{array}$ & $\begin{array}{c}\text { CASPT2 } \\
\text { Reference } \\
\text { Weight }\end{array}$ & $\begin{array}{c}\text { \% Dominant } \\
\text { Configuration }\end{array}$ \\
\hline 11-et & 2.69 & 23.47 & 0.624 & $100 \%$ \\
\hline nonet & 1.95 & 17.81 & 0.624 & $11 \%$ \\
\hline septet & 1.25 & 12.09 & 0.623 & $2.7 \%$ \\
\hline quintet & 0.65 & 7.00 & 0.622 & $1.1 \%$ \\
\hline triplet & 0.22 & 2.91 & 0.621 & $0.79 \%$ \\
\hline singlet & 0 & 0 & 0.621 & $0.85 \%$ \\
\hline
\end{tabular}


Table S5: CASSCF and CASPT2 relative energies (in $\mathrm{kJ} / \mathrm{mol}$ ), CASPT2 reference weight, and percent contribution to the wavefunction of the most dominant configuration for $\left[\mathrm{Fe}^{4+} \mathrm{Fe}^{4+} \mathrm{O}_{\mathrm{t}}\right]$.

\begin{tabular}{|c|c|c|c|c|}
\hline & $\begin{array}{c}\text { CASSCF(8,8) } \\
\text { Energy (kJ/mol) }\end{array}$ & $\begin{array}{c}\text { CASPT2(8,8) } \\
\text { Energy (kJ/mol) }\end{array}$ & $\begin{array}{c}\text { CASPT2 } \\
\text { Reference } \\
\text { Weight }\end{array}$ & $\begin{array}{c}\text { \% Dominant } \\
\text { Configuration }\end{array}$ \\
\hline nonet & -0.46 & 6.62 & 0.542 & $100 \%$ \\
\hline septet & -0.18 & 7.27 & 0.542 & $13 \%$ \\
\hline quintet & -0.06 & 5.88 & 0.542 & $4.0 \%$ \\
\hline triplet & -0.01 & 3.23 & 0.541 & $2.2 \%$ \\
\hline singlet & 0 & 0 & 0.541 & $2.8 \%$ \\
\hline
\end{tabular}

Table S6: CASSCF and CASPT2 relative energies (in $\mathrm{kJ} / \mathrm{mol}$ ), CASPT2 reference weight, and percent contribution to the wavefunction of the most dominant configuration for $\left[\mathrm{Fe}^{3+} \mathrm{Fe}^{3+}\right]_{\mathrm{t}}$.

\begin{tabular}{|c|c|c|c|c|}
\hline & $\begin{array}{c}\text { CASSCF(10,10) } \\
\text { Energy (kJ/mol) }\end{array}$ & $\begin{array}{c}\text { CASPT2(10,10) } \\
\text { Energy (kJ/mol) }\end{array}$ & $\begin{array}{c}\text { CASPT2 } \\
\text { Reference } \\
\text { Weight }\end{array}$ & $\begin{array}{c}\text { \% Dominant } \\
\text { Configuration }\end{array}$ \\
\hline 11-et & -0.06 & 18.29 & 0.619 & $100 \%$ \\
\hline nonet & 0.11 & 14.50 & 0.618 & $11 \%$ \\
\hline septet & 0.13 & 10.20 & 0.617 & $2.6 \%$ \\
\hline quintet & 0.09 & 6.11 & 0.616 & $1.0 \%$ \\
\hline triplet & 0.04 & 2.64 & 0.615 & $0.65 \%$ \\
\hline singlet & 0 & 0 & 0.614 & $0.93 \%$ \\
\hline
\end{tabular}

To verify our CASSCF/CASPT2 calculations, we also characterized the four clusters at the RASSCF/RASPT2 levels of theory by including the active space from the CASSCF calculations in the RAS2 subspace and including oxygen $p$ orbitals in the RAS1 subspace. A significant change in the Mulliken spin density on an oxygen atom from the CAS calculation to the RAS calculation would indicate the importance of including the oxygen $\mathrm{p}$ orbital in the active space. Tables S7-S10 show the comparison between the Mulliken spin densities obtained from the CASSCF calculations and the Mulliken spin densities obtained from the RASSCF calculations for all four clusters. Scheme S1 shows the labels of the atoms that are used in Tables S7-S10. The columns highlighted in green represent the RASSCF active spaces chosen for subsequent RASSCF/RASPT2 calculations for all spin states of the clusters. 


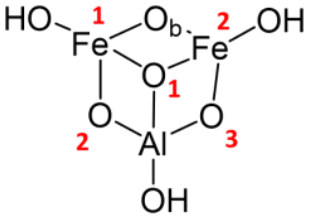

(a)

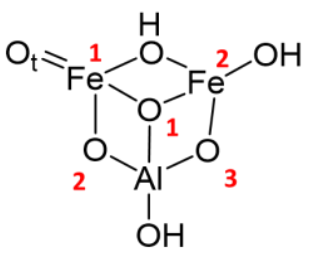

(b)

Scheme S1: Atom labels used in Tables S7-S10 for (a) oxidized cluster with $\mathrm{O}_{\mathrm{b}}$ site (the reduced cluster would have an $\mathrm{O}_{\mathrm{b}}$ vacancy) and (b) oxidized cluster with $\mathrm{O}_{\mathrm{t}}$ site (the reduced cluster would have an $\mathrm{O}_{\mathrm{t}}$ vacancy).

For species $\left[\mathrm{Fe}^{4+} \mathrm{Fe}^{4+} \mathrm{O}_{\mathrm{t}}\right]$, we attempted the active spaces shown in Table S7.

$\operatorname{RASSCF}(12,20) /(8,8) / 2, \operatorname{RASSCF}(14,22) /(8,8) / 2$, and $\operatorname{RASSCF}(16,24) /(8,8) / 2$ correspond to the addition of 2, 3, and 4 oxygen p orbitals. As shown in Table S7, the energy of the system is lowered with the addition of orbitals to the active space. Because $\operatorname{RASSCF}(14,22) /(8,8) / 2$ and RASSCF $(16,24) /(8,8) / 2$ resulted in high computational cost for subsequent RASPT2 calculations, we chose the final active space from the three versions of $\operatorname{RASSCF}(12,20) /(8,8) / 2$. Version 3 was chosen due to its lower energy and increase in $\mathrm{O}_{\mathrm{t}}$ spin density of 0.121 a.u. The oxygen p orbitals in version 3 of the $\operatorname{RASSCF}(12,20) /(8,8) / 2$ active space are shown in Figure S13.

Table S7: Mulliken spin densities obtained for $\operatorname{CASSCF}(8,8)$ and several RASSCF calculations for $\left[\mathrm{Fe}^{4+} \mathrm{Fe}^{4+} \mathrm{O}_{\mathrm{t}}\right]$ at its highest possible spin multiplicity of 9 .

\begin{tabular}{|c|c|c|c|c|c|c|c|}
\hline Atom & $\begin{array}{c}\text { CASSCF } \\
(8,8)\end{array}$ & $\begin{array}{c}\text { RASSCF } \\
(12,20) / \\
(8,8) / 2 \\
\text { Version } 1 \\
\end{array}$ & $\begin{array}{c}\text { RASSCF } \\
(12,20) / \\
(8,8) / 2 \\
\text { Version } 2 \\
\end{array}$ & $\begin{array}{c}\text { RASSCF } \\
(12,20) / \\
(8,8) / 2 \\
\text { Version } 3 \\
\end{array}$ & $\begin{array}{c}\text { RASSCF } \\
(\mathbf{1 4 , 2 2}) / \\
(\mathbf{8 , 8}) / 2\end{array}$ & $\begin{array}{c}\text { RASSCF } \\
(16,24) / \\
(8,8) / 2 \\
\text { Version } 1 \\
\end{array}$ & $\begin{array}{c}\text { RASSCF } \\
(16,24) / \\
(8,8) / 2 \\
\text { Version } 2 \\
\end{array}$ \\
\hline $\mathbf{O}_{\mathrm{t}}$ & 0.114 & -0.150 & 0.030 & 0.235 & 0.235 & 0.072 & 0.232 \\
\hline Fe1 & 3.779 & 4.024 & 3.847 & 3.65 & 3.654 & 3.808 & 3.657 \\
\hline $\mathrm{Fe} 2$ & 3.773 & 4.018 & 3.777 & 3.966 & 3.966 & 3.949 & 3.968 \\
\hline 01 & 0.043 & 0.044 & 0.047 & 0.039 & 0.039 & 0.038 & 0.040 \\
\hline $\mathbf{O 2}$ & 0.071 & 0.081 & 0.083 & -0.106 & 0.073 & 0.079 & 0.072 \\
\hline 03 & 0.081 & -0.159 & 0.080 & 0.005 & -0.106 & -0.091 & -0.108 \\
\hline Energy (Hartree) & -3311.368 & -3311.606 & -3311.568 & -3311.607 & -3311.638 & -3311.656 & -3311.676 \\
\hline
\end{tabular}




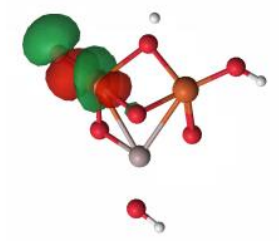

(a)

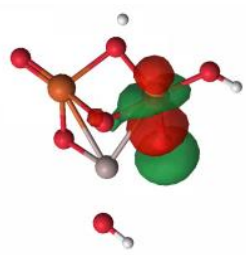

(b)

Figure S13: Optimized RAS1 oxygen orbitals from the $\operatorname{RASSCF}(12,20) /(8,8) / 2$ calculation for the nonet spin state of $\left[\mathrm{Fe}^{4+} \mathrm{Fe}^{4+} \mathrm{O}_{\mathrm{t}}\right]$.

For species $\left[\mathrm{Fe}^{4+} \mathrm{O}_{\mathrm{b}} \mathrm{Fe}^{4+}\right]$, we attempted the active spaces shown in Table $\mathrm{S} 8$.

$\operatorname{RASSCF}(12,20) /(8,8) / 2, \operatorname{RASSCF}(14,22) /(8,8) / 2$, and $\operatorname{RASSCF}(16,24) /(8,8) / 2$ correspond to the addition of 2, 3, and 4 oxygen p orbitals. As for $\left[\mathrm{Fe}^{4+} \mathrm{Fe}^{4+} \mathrm{O}_{\mathrm{t}}\right]$, the energy of the system is lowered with the addition of orbitals to the active space as shown in Table S8. Because

$\operatorname{RASSCF}(14,22) /(8,8) / 2$ and $\operatorname{RASSCF}(16,24) /(8,8) / 2$ resulted in high computational cost for subsequent RASPT2 calculations, we chose the final active space from the three versions of $\operatorname{RASSCF}(12,20) /(8,8) / 2$. Version 3 was chosen due to its lower energy and change in the spin densities of $\mathrm{O} 2$ and $\mathrm{O} 3$ of about 0.24 a.u. The oxygen $\mathrm{p}$ orbitals in version 3 of the $\operatorname{RASSCF}(12,20) /(8,8) / 2$ active space are shown in Figure S14.

Table S8: Mulliken spin densities obtained for $\operatorname{CASSCF}(8,8)$ and several RASSCF calculations for $\left[\mathrm{Fe}^{4+} \mathrm{O}_{\mathrm{b}} \mathrm{Fe}^{4+}\right]$ at its highest possible spin multiplicity of 9 .

\begin{tabular}{|c|c|c|c|c|c|c|}
\hline & $\begin{array}{c}\text { CASSCF } \\
(\mathbf{8 , 8})\end{array}$ & $\begin{array}{c}\text { RASSCF } \\
(\mathbf{1 2 , 2 0}) /(\mathbf{8 , 8}) / \mathbf{2} \\
\text { Version 1 }\end{array}$ & $\begin{array}{c}\text { RASSCF } \\
\mathbf{( 1 2 , 2 0}) /(\mathbf{8 , 8}) / \mathbf{2} \\
\text { Version 2 }\end{array}$ & $\begin{array}{c}\text { RASSCF } \\
(\mathbf{1 2 , 2 0}) /(\mathbf{8 , 8}) / \mathbf{2} \\
\text { Version 3 }\end{array}$ & $\begin{array}{c}\text { RASSCF } \\
(\mathbf{1 4 , 2 2}) /(\mathbf{8 , 8}) / 2\end{array}$ & $\begin{array}{c}\text { RASSCF } \\
(\mathbf{1 6 , 2 4}) /(\mathbf{8 , 8}) / 2\end{array}$ \\
\hline $\mathbf{O}_{\mathbf{b}}$ & 0.187 & -0.1012 & -0.1032 & 0.2001 & 0.0366 & 0.3638 \\
\hline $\mathbf{F e 1}$ & 3.727 & 3.9577 & 3.7498 & 3.9728 & 3.9418 & 3.8543 \\
\hline $\mathbf{F e 2}$ & 3.727 & 4.0017 & 3.969 & 3.968 & 3.8714 & 3.8013 \\
\hline $\mathbf{O 1}$ & 0.045 & 0.0379 & 0.0427 & 0.0327 & 0.0384 & 0.0314 \\
\hline $\mathbf{O 2}$ & 0.092 & 0.1198 & 0.0788 & -0.1501 & -0.1443 & -0.1034 \\
\hline $\mathbf{O 3}$ & 0.092 & -0.1617 & 0.1192 & -0.1438 & 0.1167 & -0.0589 \\
\hline $\begin{array}{c}\text { Energy } \\
(\text { Hartree })\end{array}$ & -3311.361 & -3311.560 & -3311.512 & -3311.563 & -3311.587 & -3311.626 \\
\hline
\end{tabular}

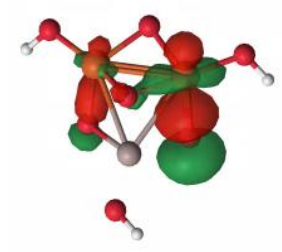

(a)

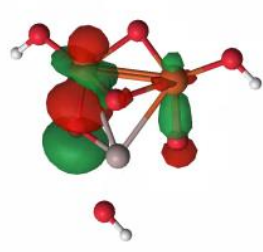

(b)

Figure S14: Optimized RAS1 oxygen orbitals from the RASSCF $(12,20) /(8,8) / 2$ calculation for the nonet spin state of $\left[\mathrm{Fe}^{4+} \mathrm{O}_{\mathrm{b}} \mathrm{Fe}^{4+}\right]$. 
Lastly, for species $\left[\mathrm{Fe}^{3+} \mathrm{Fe}^{3+}\right]_{\mathrm{t}}$ and $\left[\mathrm{Fe}^{3+} \mathrm{Fe}^{3+}\right]_{\mathrm{b}}$, we attempted the active spaces shown in Tables S9-S10. RASSCF $(12,22) /(10,10) / 2, \operatorname{RASSCF}(14,24) /(10,10) / 2, \operatorname{RASSCF}(16,26) /(10,10) / 2$, and $\operatorname{RASSCF}(18,28) /(10,10) / 2$ correspond to the addition of $1,2,3$, and 4 oxygen $p$ orbitals. As for $\left[\mathrm{Fe}^{4+} \mathrm{Fe}^{4+} \mathrm{O}_{\mathrm{t}}\right]$ and $\left[\mathrm{Fe}^{4+} \mathrm{O}_{\mathrm{b}} \mathrm{Fe}^{4+}\right]$, the energy of the system is lowered with the addition of orbitals to the active space as shown in Tables S9-S10. Because $\operatorname{RASSCF}(14,24) /(10,10) / 2$,

$\operatorname{RASSCF}(16,26) /(10,10) / 2$, and $\operatorname{RASSCF}(18,28) /(10,10) / 2$ resulted in high computational cost for subsequent RASPT2 calculations, we chose $\operatorname{RASSCF}(12,22) /(8,8) / 2$ for subsequent RASPT2 calculations. An increase in Mulliken spin density of 0.1 and 0.04 is observed on $\mathrm{O} 1$ for $\left[\mathrm{Fe}^{3+} \mathrm{Fe}^{3+}\right]_{\mathrm{t}}$ and $\left[\mathrm{Fe}^{3+} \mathrm{Fe}^{3+}\right]_{\mathrm{b}}$, respectively. The oxygen $\mathrm{p}$ orbitals in the $\operatorname{RASSCF}(12,20) /(8,8) / 2$ active spaces for each cluster are shown in Figure S15.

Table S9: Mulliken spin densities obtained for $\operatorname{CASSCF}(10,10)$ and several RASSCF calculations for $\left[\mathrm{Fe}^{3+} \mathrm{Fe}^{3+}\right]_{\mathrm{t}}$ at its highest possible spin multiplicity of 11 .

\begin{tabular}{|c|c|c|c|c|c|}
\hline & $\begin{array}{c}\text { CASSCF } \\
(\mathbf{1 0 , 1 0})\end{array}$ & $\begin{array}{c}\text { RASSCF } \\
(\mathbf{1 2 , 2 2}) /(\mathbf{1 0 , 1 0}) / \mathbf{2}\end{array}$ & $\begin{array}{c}\text { RASSCF } \\
(\mathbf{1 4 , 2 4}) /(\mathbf{1 0 , 1 0}) / \mathbf{2}\end{array}$ & $\begin{array}{c}\text { RASSCF } \\
(\mathbf{1 6 , 2 6}) /(\mathbf{1 0 , 1 0}) / \mathbf{2}\end{array}$ & $\begin{array}{c}\text { RASSCF } \\
(\mathbf{1 8 , 2 8}) /(\mathbf{1 0 , 1 0}) / \mathbf{2}\end{array}$ \\
\hline Fe1 & 4.676 & 4.581 & 4.582 & 4.433 & 4.371 \\
\hline Fe2 & 4.744 & 4.743 & 4.683 & 4.687 & 4.693 \\
\hline O1 & 0.140 & 0.239 & 0.240 & 0.224 & 0.202 \\
\hline O2 & 0.169 & 0.165 & 0.164 & 0.329 & 0.417 \\
\hline O3 & 0.113 & 0.113 & 0.171 & 0.166 & 0.159 \\
\hline Energy (Hartree) & -3236.743 & -3236.834 & -3236.857 & -3236.885 & -3236.929 \\
\hline
\end{tabular}

Table S10: Mulliken spin densities obtained for CASSCF $(10,10)$ and several RASSCF calculations for $\left[\mathrm{Fe}^{3+} \mathrm{Fe}^{3+}\right]_{\mathrm{b}}$ at its highest possible spin multiplicity of 11 .

\begin{tabular}{|c|c|c|c|c|c|}
\hline & $\begin{array}{c}\text { CASSCF } \\
(\mathbf{1 0 , 1 0})\end{array}$ & $\begin{array}{c}\text { RASSCF } \\
(\mathbf{1 2 , 2 2}) /(\mathbf{1 0 , 1 0}) / 2\end{array}$ & $\begin{array}{c}\text { RASSCF } \\
(\mathbf{1 4 , 2 4}) /(\mathbf{1 0 , 1 0}) / \mathbf{2}\end{array}$ & $\begin{array}{c}\text { RASSCF } \\
(\mathbf{1 6 , 2 6}) /(\mathbf{1 0}, \mathbf{1 0}) / \mathbf{2}\end{array}$ & $\begin{array}{c}\text { RASSCF } \\
(\mathbf{1 8 , 2 8}) /(\mathbf{1 0 , 1 0}) / \mathbf{2}\end{array}$ \\
\hline Fe1 & 4.744 & 4.715 & 4.7052 & 4.7059 & 4.6567 \\
\hline Fe2 & 4.744 & 4.737 & 4.7061 & 4.6544 & 4.6564 \\
\hline O1 & 0.105 & 0.140 & 0.1843 & 0.1818 & 0.1795 \\
\hline O2 & 0.121 & 0.122 & 0.1206 & 0.1199 & 0.1717 \\
\hline O3 & 0.123 & 0.123 & 0.1222 & 0.1767 & 0.1746 \\
\hline Energy (Hartree) & -3236.763 & -3236.848 & -3236.886 & -3236.909 & -3236.931 \\
\hline
\end{tabular}

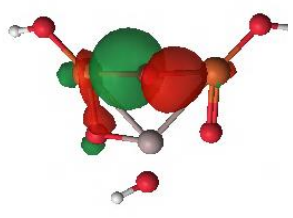

(a)

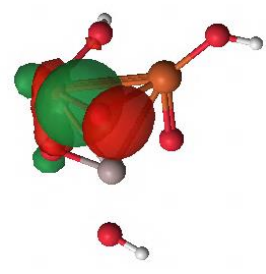

(b)

Figure S15: Optimized RAS1 oxygen orbitals from the $\operatorname{RASSCF}(12,22) /(10,10) / 2$ calculations for (a) $\left[\mathrm{Fe}^{3+} \mathrm{Fe}^{3+}\right]_{\mathrm{b}}$ and (b) $\left[\mathrm{Fe}^{3+} \mathrm{Fe}^{3+}\right]_{\mathrm{t}}$ in their 11-et spin state. 
The multireference calculations were carried out by RASSCF and RASPT2 using the orbitals from the initial RASSCF calculation for all possible spin states. These results are shown in Tables S11-S14. For all spin states and all clusters, the active orbitals in RAS2 (Fe d orbitals) have an electron occupation between 0.95 and 1.05, and the active orbitals in RAS 1 (oxygen $p$ orbitals) have an occupation between 1.80 and 2.00. Our RASSCF/RASPT2 results show that all lower spin states for the four diiron species are highly multiconfigurational as they exhibit a percentage of the dominant configuration of no more than $12 \%$. The percent dominant configuration values of $79 \%$ and $77 \%$ for the nonet states of the reduced clusters, and the percent dominant configuration values of $97 \%$ and $96 \%$ for the 11 -et states of the oxidized clusters correspond to the ferromagnetic coupling of electrons between the iron atoms and doubly occupied oxygen p orbitals. The inclusion of electron dynamic correlation in RASPT2 widens the spin state energy ladder obtained from RASSCF. Our RASPT2 results show that the singlet state is the lowest in energy for all clusters, and between $3.5-30 \mathrm{~kJ} / \mathrm{mol}$ lower in energy than the highest spin states. The relative energies for the intermediate spin states lie between the singlet and highest possible spin state (nonet for the oxidized cluster, 11-et for the reduced cluster) for $\left[\mathrm{Fe}^{4+} \mathrm{O}_{\mathrm{b}} \mathrm{Fe}^{4+}\right],\left[\mathrm{Fe}^{3+} \mathrm{Fe}^{3+}\right]_{\mathrm{b}}$ and $\left[\mathrm{Fe}^{3+} \mathrm{Fe}^{3+}\right]_{\mathrm{t}}$. As observed from the CASPT2 calculations, our RASPT2 results show that the spin state with the highest energy for $\left[\mathrm{Fe}^{4+} \mathrm{Fe}^{4+} \mathrm{O}_{\mathrm{t}}\right]$ is the septet state rather than the highest possible spin state, which is what is observed for the rest of the clusters. However, it is only $1.35 \mathrm{~kJ} / \mathrm{mol}$ higher in energy than the nonet spin state.

Table S11: RASSCF and RASPT2 relative energies (in kJ/mol), RASPT2 reference weight, and percent contribution to the wavefunction of the most dominant configuration for $\left[\mathrm{Fe}^{4+} \mathrm{O}_{\mathrm{b}} \mathrm{Fe}^{4+}\right]$.

\begin{tabular}{|c|c|c|c|c|}
\hline & $\begin{array}{c}\text { RASSCF } \\
\mathbf{( 1 2 , 2 0}) /(\mathbf{8 , 8}) / 2 \\
\text { Energy (kJ/mol) }\end{array}$ & $\begin{array}{c}\text { RASPT2(12,20)/(8,8)/2 } \\
\text { Energy (kJ/mol) }\end{array}$ & $\begin{array}{c}\text { RASPT2 } \\
\text { Reference } \\
\text { Weight }\end{array}$ & $\begin{array}{c}\text { \% Dominant } \\
\text { Configuration }\end{array}$ \\
\hline nonet & 5.78 & 29.13 & 0.577 & $79 \%$ \\
\hline septet & 3.94 & 21.86 & 0.576 & $12 \%$ \\
\hline quintet & 2.16 & 12.53 & 0.574 & $4.1 \%$ \\
\hline triplet & 0.76 & 4.90 & 0.572 & $2.4 \%$ \\
\hline singlet & 0 & 0 & 0.572 & $2.7 \%$ \\
\hline
\end{tabular}


Table S12: RASSCF and RASPT2 relative energies (in kJ/mol), RASPT2 reference weight, and percent contribution to the wavefunction of the most dominant configuration for $\left[\mathrm{Fe}^{3+} \mathrm{Fe}^{3+}\right]_{b}$. \#N/A indicates that the calculation did not finish due to high computational cost for the triplet spin state of the RASPT2 calculation.

\begin{tabular}{|c|c|c|c|c|}
\hline & $\begin{array}{c}\text { RASSCF(12,22)/ } \\
\mathbf{( 1 0 , 1 0 ) / 2} \\
\text { Energy (kJ/mol) }\end{array}$ & $\begin{array}{c}\text { RASPT2(12,22)/ } \\
\mathbf{( 1 0 , 1 0 ) / 2} \\
\text { Energy (kJ/mol) }\end{array}$ & $\begin{array}{c}\text { RASPT2 } \\
\text { Reference } \\
\text { Weight }\end{array}$ & $\begin{array}{c}\text { \% Dominant } \\
\text { Configuration }\end{array}$ \\
\hline 11-et & 4.62 & 18.20 & 0.630 & $97 \%$ \\
\hline nonet & 3.26 & 14.02 & 0.630 & $11 \%$ \\
\hline septet & 2.05 & 9.21 & 0.629 & $2.9 \%$ \\
\hline quintet & 1.05 & 5.26 & 0.628 & $1.1 \%$ \\
\hline triplet & 0.36 & \#N/A & \#N/A & $.87 \%$ \\
\hline singlet & 0 & 0 & 0.627 & $1.0 \%$ \\
\hline
\end{tabular}

Table S13: RASSCF and RASPT2 relative energies (in $\mathrm{kJ} / \mathrm{mol}$ ), RASPT2 reference weight, and percent contribution to the wavefunction of the most dominant configuration for $\left[\mathrm{Fe}^{4+} \mathrm{Fe}^{4+} \mathrm{O}_{\mathrm{t}}\right]$.

\begin{tabular}{|c|c|c|c|c|}
\hline & $\begin{array}{c}\text { RASSCF } \\
\mathbf{( 1 2 , 2 0 ) / ( 8 , 8 ) / 2} \\
\text { Energy (kJ/mol) }\end{array}$ & $\begin{array}{c}\text { RASPT2(12,20)/(8,8)/2 } \\
\text { Energy (kJ/mol) }\end{array}$ & $\begin{array}{c}\text { RASPT2 } \\
\text { Reference } \\
\text { Weight }\end{array}$ & $\begin{array}{c}\text { \% Dominant } \\
\text { Configuration }\end{array}$ \\
\hline nonet & -0.01 & 2.22 & 0.594 & $77 \%$ \\
\hline septet & 0.09 & 3.57 & 0.594 & $9.9 \%$ \\
\hline quintet & 0.08 & 2.71 & 0.594 & $3.0 \%$ \\
\hline triplet & 0.03 & 1.43 & 0.594 & $1.7 \%$ \\
\hline singlet & 0 & 0 & 0.594 & $2.1 \%$ \\
\hline
\end{tabular}

Table S14: RASSCF and RASPT2 relative energies (in $\mathrm{kJ} / \mathrm{mol}$ ), RASPT2 reference weight, and percent contribution to the wavefunction of the most dominant configuration for $\left[\mathrm{Fe}^{3+} \mathrm{Fe}^{3+}\right]_{\mathrm{t}}$.

\begin{tabular}{|c|c|c|c|c|}
\hline & $\begin{array}{c}\text { RASSCF(12,22)/ } \\
\mathbf{( 1 0 , 1 0 ) / 2} \\
\text { Energy (kJ/mol) }\end{array}$ & $\begin{array}{c}\text { RASPT2(12,22)/ } \\
\mathbf{( 1 0 , 1 0 ) / 2} \\
\text { Energy (kJ/mol) }\end{array}$ & $\begin{array}{c}\text { RASPT2 } \\
\text { Reference } \\
\text { Weight }\end{array}$ & $\begin{array}{c}\text { \% Dominant } \\
\text { Configuration }\end{array}$ \\
\hline 11-et & 0.45 & 10.50 & 0.624 & $96 \%$ \\
\hline nonet & 0.43 & 9.46 & 0.623 & $8.7 \%$ \\
\hline septet & 0.32 & 6.62 & 0.622 & $2.4 \%$ \\
\hline quintet & 0.18 & 3.90 & 0.622 & $0.99 \%$ \\
\hline triplet & 0.07 & 1.63 & 0.620 & $0.64 \%$ \\
\hline singlet & 0 & 0 & 0.620 & $0.72 \%$ \\
\hline
\end{tabular}


Figures S16-S19 show a summary of our CASSCF/CASPT2 and RASSCF/RASPT2 calculations. Overall, the addition of electron dynamic correlation in CASPT2 and RASPT2 widens the spin state energy ladder predicted by CASSCF and RASSCF. CASPT2 and RASPT2 predict the same spin ordering for all clusters, demonstrating that CASPT2 is sufficient to describe the systems. For the most part, the singlet state is predicted to be lowest in energy, while the highest possible spin states, the nonet and 11-et states of the reduced and oxidized clusters, respectively, are predicted to be the highest in energy. Intermediate states fall between the singlet and the highest possible spin state in terms of relative energy. This contradicts our DFT results (Figure S8), in which we generally find the open-shell singlet and the highest possible spin states to be the lowest in energy, with the intermediate states being higher in energy. Table S15 compares the difference in energy between the highest spin state and the open-shell singlet spin state at the DFT level of theory for a variety of DFT functionals and at the CASPT2/RASPT2 levels of theory.

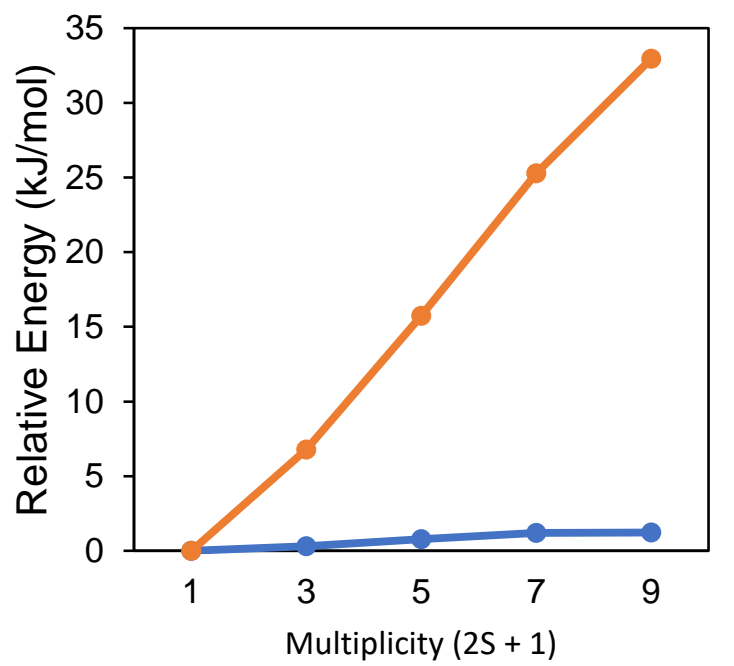

$\longrightarrow$ CASSCF energy $\longrightarrow$ CASPT2 energy

(a)

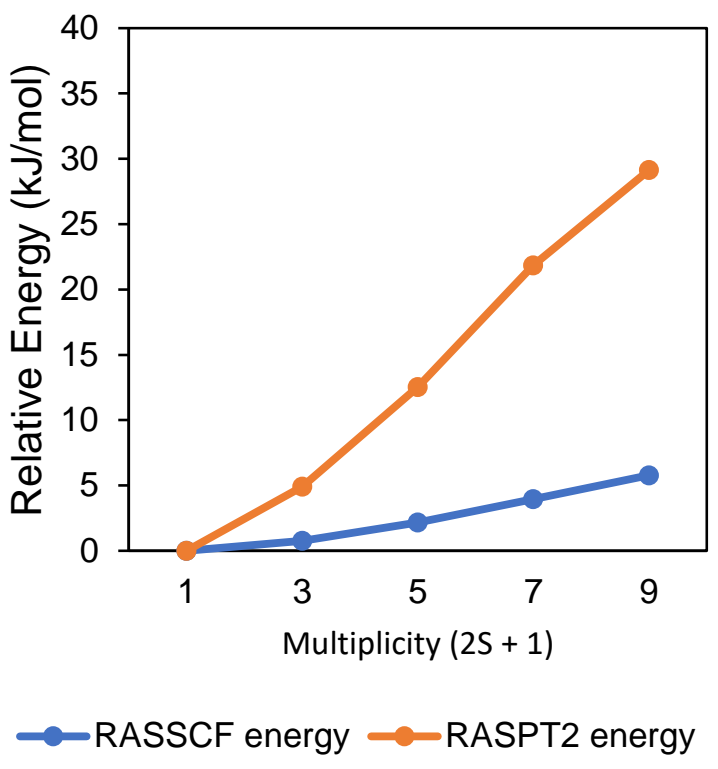

(b)

Figure S16: Line plots showing the relative energies for species $\left[\mathrm{Fe}^{4+} \mathrm{O}_{\mathrm{b}} \mathrm{Fe}^{4+}\right]$ calculated at the (a) CASSCF and CASPT2 levels of theory and (b) RASSCF and RASPT2 levels of theory. 


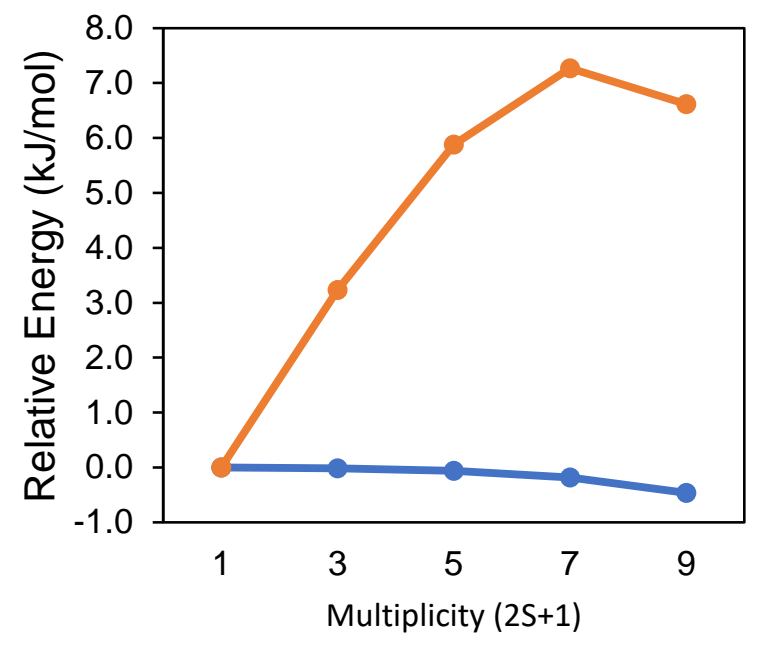

$\multimap$ CASSCF energy $\multimap$ CASPT2 energy

(a)

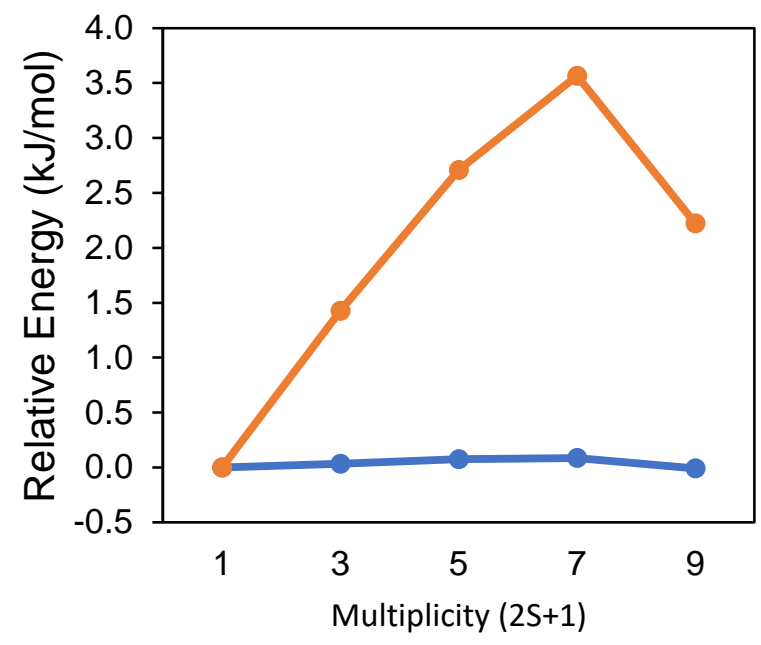

$\multimap$ RASSCF energy $\rightarrow$ RASPT2 energy

(b)

Figure S17: Line plots showing the relative energies for species $\left[\mathrm{Fe}^{4+} \mathrm{Fe}^{4+} \mathrm{O}_{\mathrm{t}}\right]$ calculated at the (a) CASSCF and CASPT2 levels of theory and (b) RASSCF and RASPT2 levels of theory.

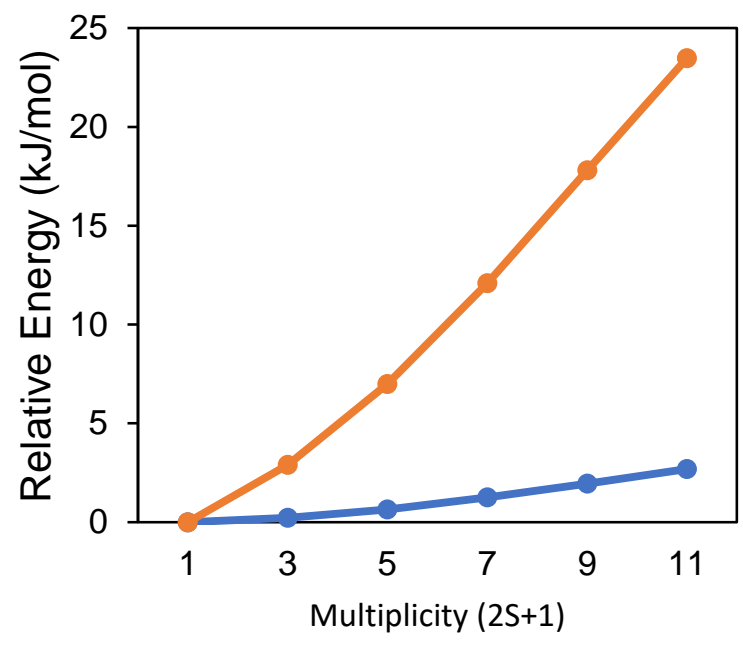

$\rightarrow$ CASSCF energy - CASPT2 energy

(a)

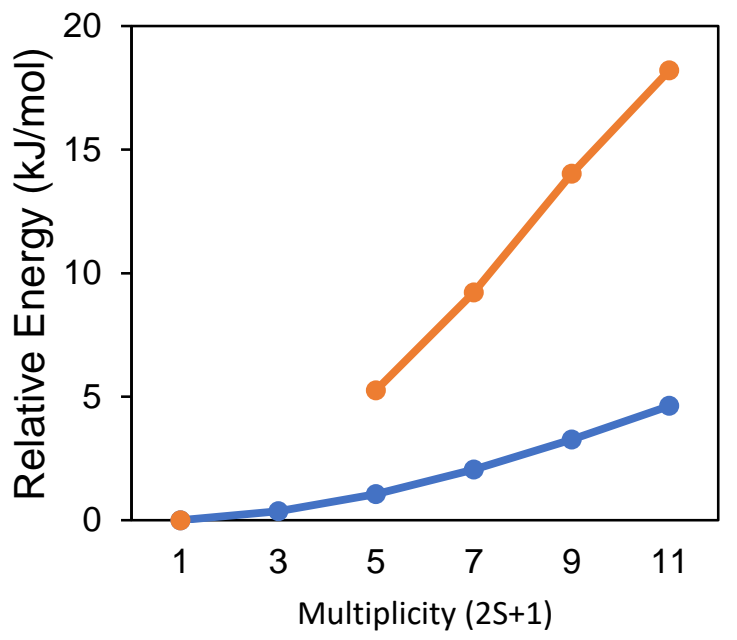

$\multimap$ RASSCF energy $\longrightarrow$ RASPT2 energy

(b)

Figure S18: Line plots showing the relative energies for species $\left[\mathrm{Fe}^{3+} \mathrm{Fe}^{3+}\right]_{\mathrm{b}}$ calculated at the (a) CASSCF and CASPT2 levels of theory and (b) RASSCF and RASPT2 levels of theory. The RASPT2 energy for multiplicity 3 is missing due to high computational cost. 


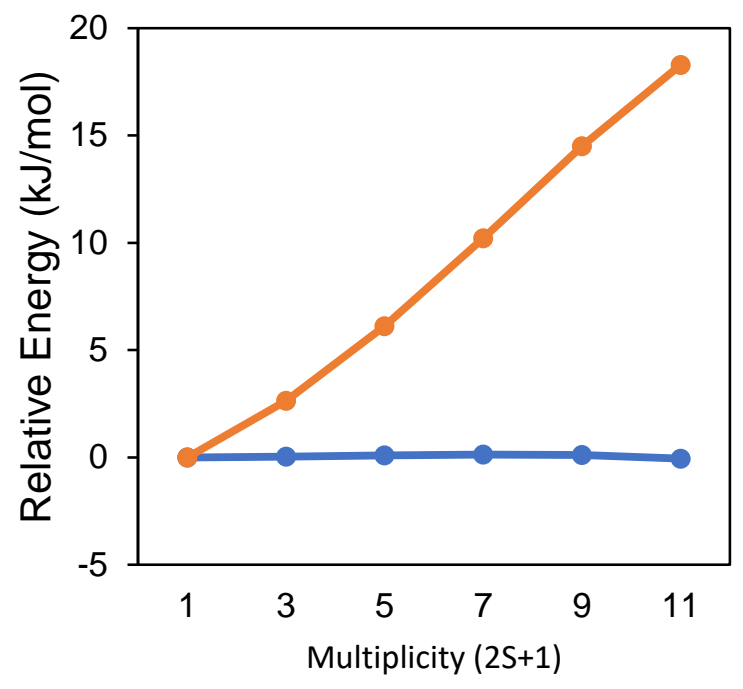

$\multimap$ CASSCF energy $\multimap$ CASPT2 energy

(a)

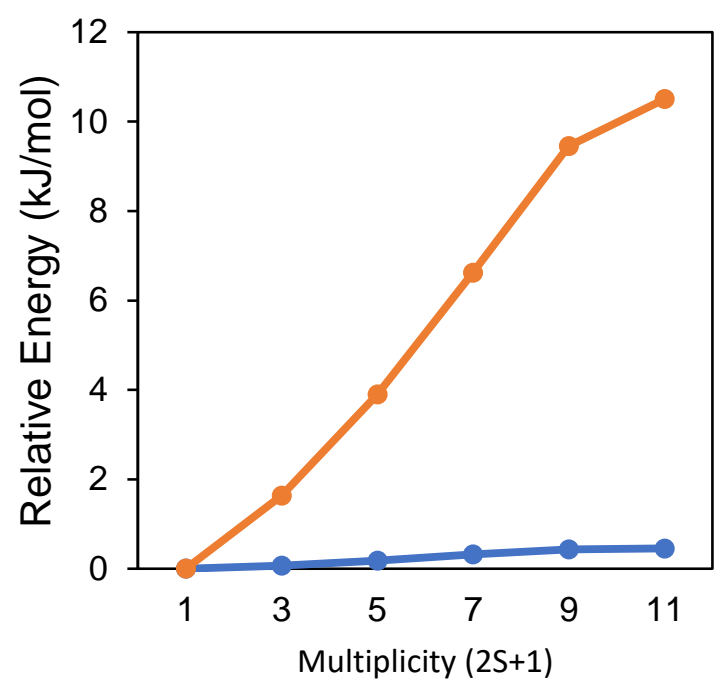

$\multimap$ RASSCF energy $\multimap-$ RASPT2 energy

(b)

Figure S19: Line plots showing the relative energies for species $\left[\mathrm{Fe}^{3+} \mathrm{Fe}^{3+}\right]_{t}$ calculated at the (a) CASSCF and CASPT2 levels of theory and (b) RASSCF and RASPT2 levels of theory.

Table S15: $\Delta$ EHS-LS in $_{\text {kJ } / m o l}$ at various levels of theory for species $\left[\mathrm{Fe}^{4+} \mathrm{O}_{b} \mathrm{Fe}^{4+}\right],\left[\mathrm{Fe}^{4+} \mathrm{Fe}^{4+} \mathrm{O}_{\mathrm{t}}\right]$, $\left[\mathrm{Fe}^{3+} \mathrm{Fe}^{3+}\right]_{\mathrm{b}}$, and $\left[\mathrm{Fe}^{3+} \mathrm{Fe}^{3+}\right]_{\mathrm{t}}$.

\begin{tabular}{|l|l|l|l|l|l|l|l|}
\hline & M06-L & OPBE & M06 & B3LYP & PBE0 & CASPT2 & RASPT2 \\
\hline$\left[\mathrm{Fe}^{4+} \mathrm{O}_{\mathrm{b}} \mathrm{Fe}^{4+}\right]$ & 11.51 & 17.30 & 11.46 & 9.01 & 8.42 & 32.94 & 29.13 \\
\hline$\left[\mathrm{Fe}^{4+} \mathrm{Fe}^{4+} \mathrm{O}_{\mathrm{t}}\right]$ & 2.18 & 10.9 & 3.19 & 1.99 & 1.37 & 6.62 & 2.22 \\
\hline$\left[\mathrm{Fe}^{3+} \mathrm{Fe}^{3+}\right]_{\mathrm{b}}$ & 21.71 & 30.67 & 15.19 & 15.41 & 12.77 & 23.47 & 18.20 \\
\hline$\left[\mathrm{Fe}^{3+} \mathrm{Fe}^{3+}\right]_{\mathrm{t}}$ & 10.79 & 18.82 & 7.35 & 6.49 & 4.35 & 18.29 & 10.50 \\
\hline
\end{tabular}




\section{Section S6}

\section{1-et vs. nonet spin state energy surfaces}

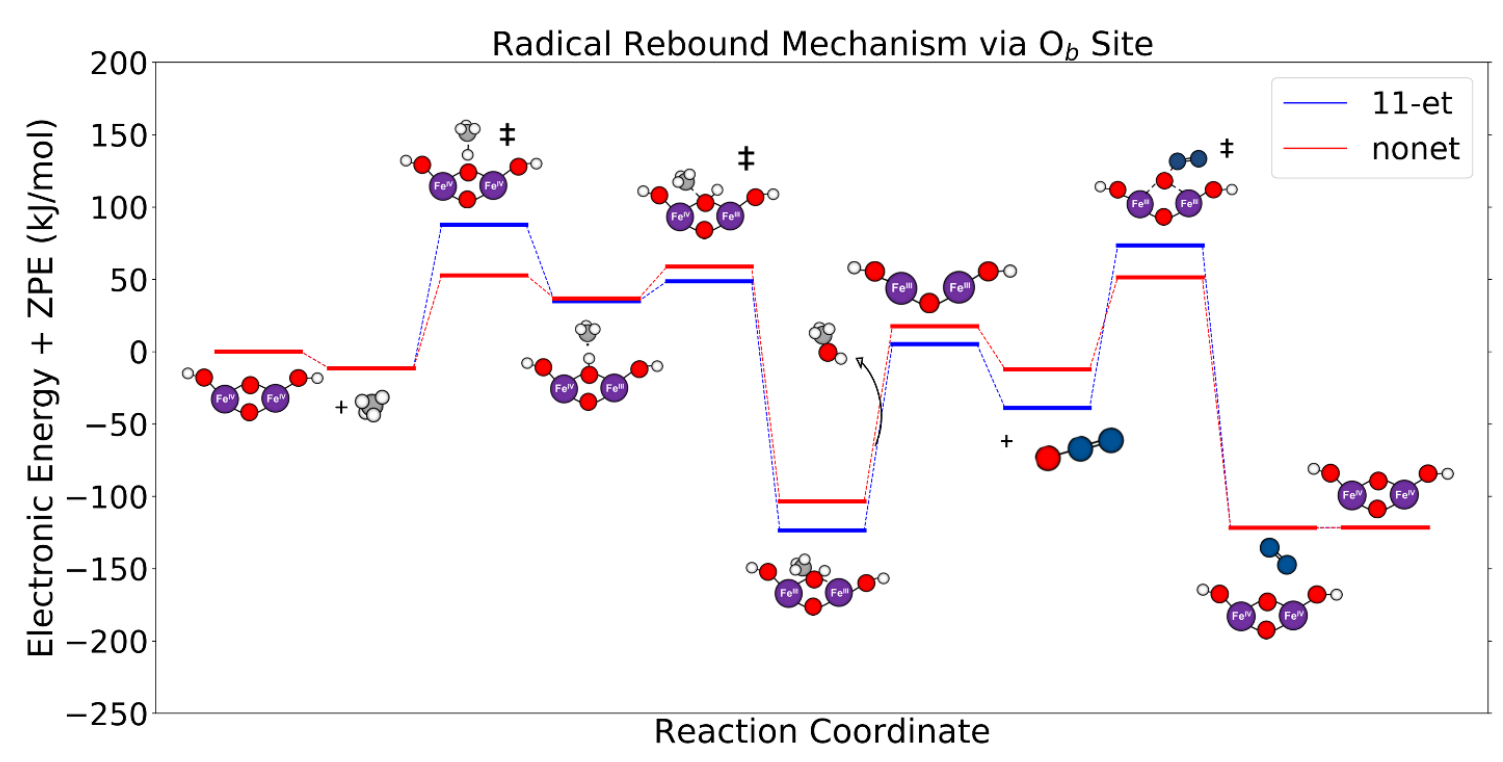

(a)

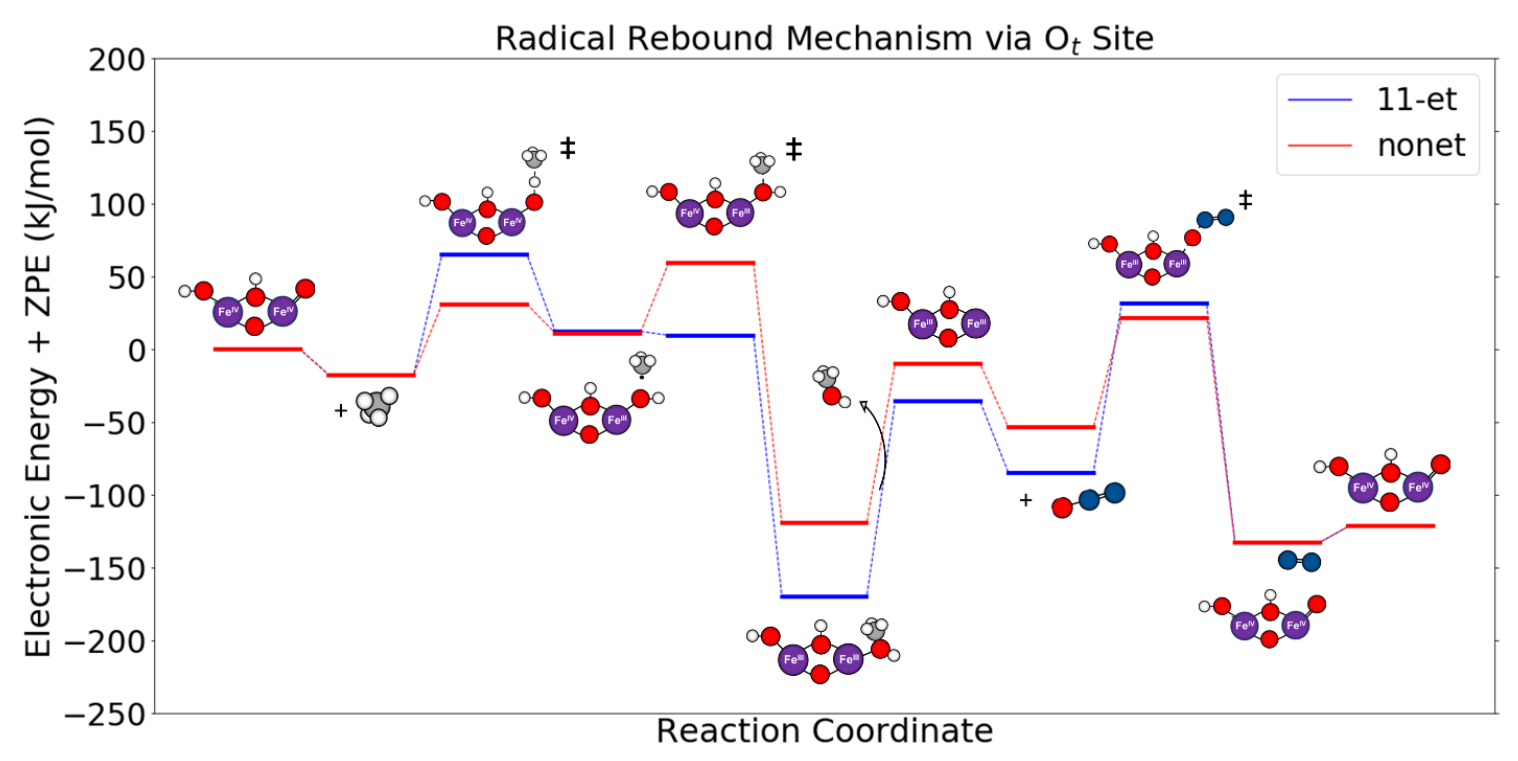

(b)

Figure S20: Radical rebound pathway via $O_{b}$ and $O_{t}$ sites. The most stable spin state for the oxidized form of the cluster $\left[\mathrm{Fe}^{4+} \mathrm{Fe}^{4+} \mathrm{O}_{\mathrm{x}}\right]$ (where $\mathrm{x}=\mathrm{b}$ or $\mathrm{t}$ ) is a nonet. The catalyst remains as a nonet through the adsorption of methane and the first transition state (H-abstraction). The nonet and 11-et spin states have nearly degenerate energies for the methyl radical intermediate. The spin state changes to an 11-et during the second transition state that corresponds to the radical attack. At this point, the catalyst is reduced to $\left[\mathrm{Fe}^{3+} \mathrm{Fe}^{3+}\right]_{\mathrm{x}}$, methanol desorbs, and the diiron cluster 
switches back to a nonet state during the third transition state $\left(\mathrm{N}_{2} \mathrm{O}\right.$ activation) to oxidize the catalyst back to $\left[\mathrm{Fe}^{4+} \mathrm{Fe}^{4+} \mathrm{O}_{\mathrm{x}}\right]$.

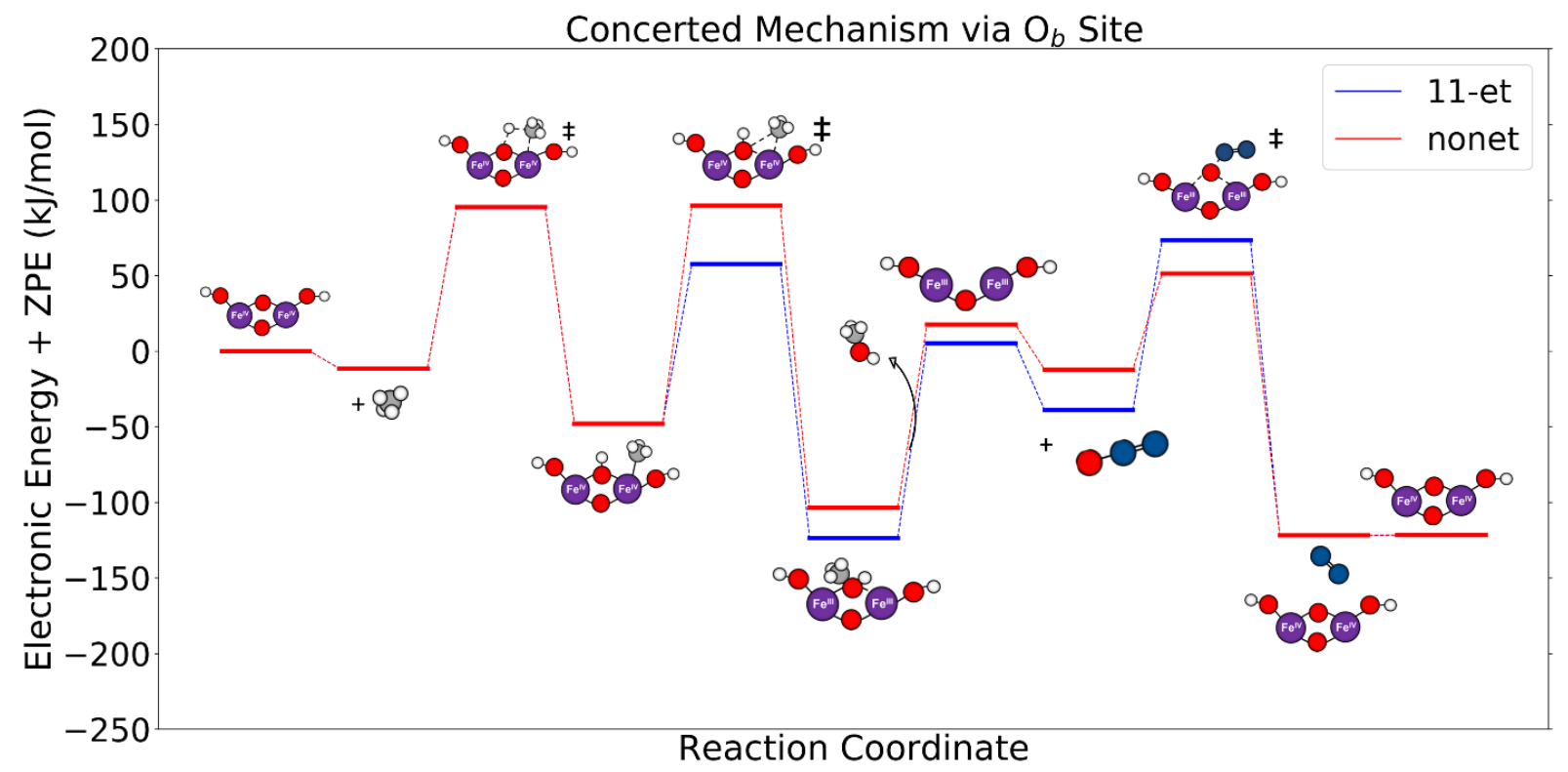

(a)

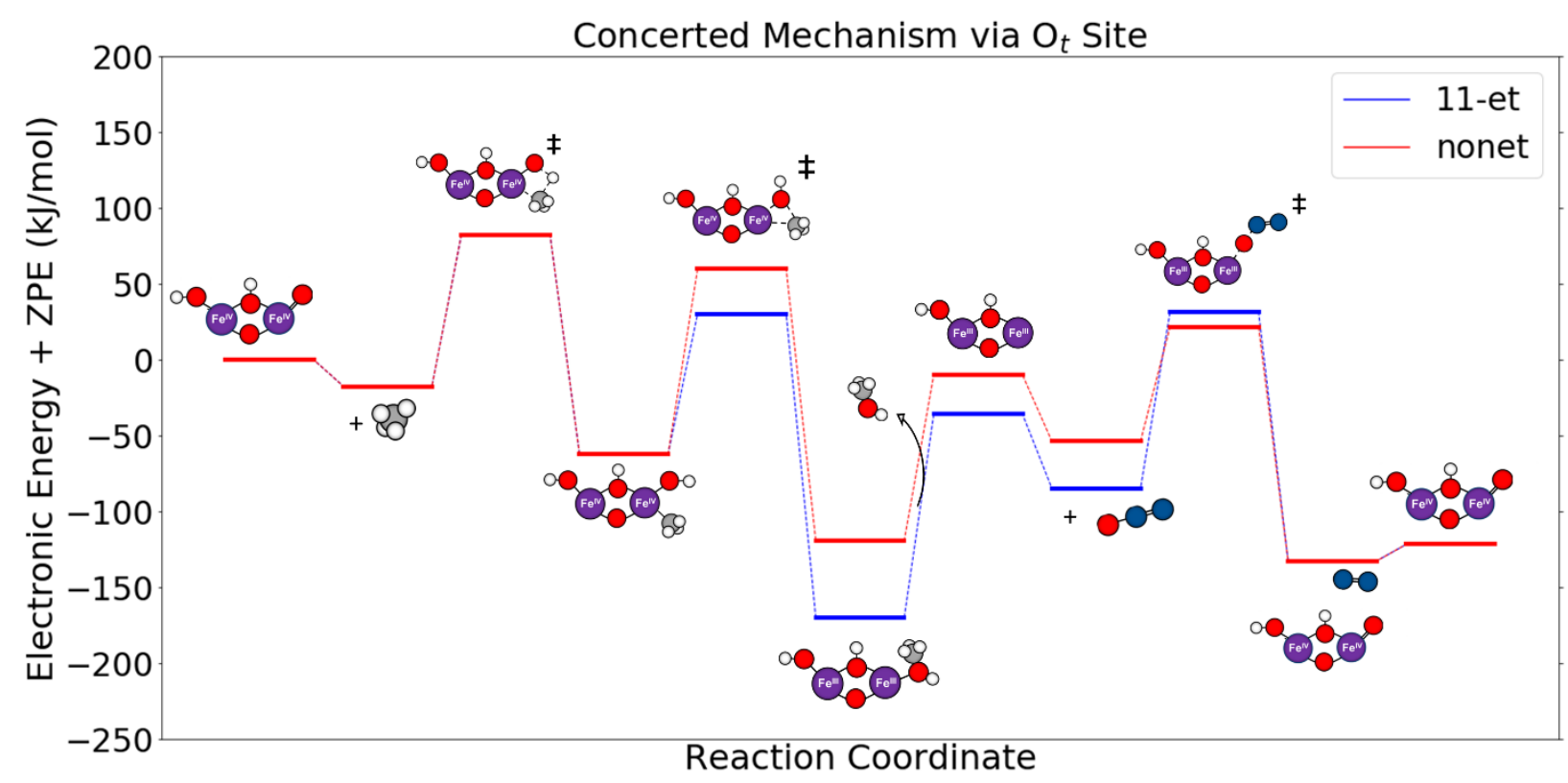

(b)

Figure S21: Concerted pathway via $\boldsymbol{O}_{b}$ and $\boldsymbol{O}_{\boldsymbol{t}}$ sites. The most stable spin state for the oxidized form of the cluster $\left[\mathrm{Fe}^{4+} \mathrm{Fe}^{4+} \mathrm{O}_{\mathrm{x}}\right]$ (where $\mathrm{x}=\mathrm{b}$ or $\mathrm{t}$ ) is a nonet. The catalyst remains as a nonet through the adsorption of methane, the first transition state $(\mathrm{C}-\mathrm{H}$ heterolytic cleavage), and the bound methyl intermediate. The spin state changes to an 11-et during the second transition state that corresponds to the $\mathrm{OH}$ and methyl recombination. At this point, the catalyst is reduced to 
$\left[\mathrm{Fe}^{3+} \mathrm{Fe}^{3+}\right]_{\mathrm{x}}$, methanol desorbs, and the diiron cluster switches back to a nonet state during the third transition state $\left(\mathrm{N}_{2} \mathrm{O}\right.$ activation) to oxidize the catalyst back to $\left[\mathrm{Fe}^{4+} \mathrm{Fe}^{4+} \mathrm{O}_{\mathrm{x}}\right]$.

Table S16: Summary of the most stable ferromagnetic spin states for each of the species in the proposed reaction mechanisms at the M06-L level of theory.

\begin{tabular}{|c|c|c|}
\hline Catalytic Species & Ob pathway & Ot pathway \\
\hline$\left[\mathrm{Fe}^{4+} \mathrm{Fe}^{4+} \mathrm{O}_{\mathrm{x}}\right]$ & 9 & 9 \\
\hline$\left[\mathrm{Fe}^{4+} \mathrm{Fe}^{4+} \mathrm{O}_{\mathrm{x}} / \mathrm{CH}_{4}\right]^{*}$ & 9 & 9 \\
\hline $\mathrm{TS} 1$ (radical-rebound) & 9 & 9 \\
\hline $\mathrm{TS} 1($ concerted $)$ & 9 & $9 / 11$ (degenerate) \\
\hline$\left[\mathrm{Fe}^{3+} \mathrm{Fe}^{4+}\left(\mathrm{O}_{\mathrm{x}}-\mathrm{H}\right){ }^{\bullet} \mathrm{CH}_{3}\right]^{*}$ & $9 / 11($ degenerate $)$ & 9 \\
\hline$\left[\mathrm{Fe}^{4+} \mathrm{Fe}^{4+}\left(\mathrm{O}_{\mathrm{x}}-\mathrm{H}\right)\left(\mathrm{CH}_{3}\right)\right]^{*}$ & 9 & 11 \\
\hline $\mathrm{TS} 2($ radical-rebound $)$ & 11 & 11 \\
\hline $\mathrm{TS} 2($ concerted $)$ & 11 & 11 \\
\hline$\left[\mathrm{Fe}^{3+} \mathrm{Fe}^{3+}\left(\mathrm{CH}_{3} \mathrm{O}_{\mathrm{x}} \mathrm{H}\right)\right]^{*}$ & 11 & 11 \\
\hline$\left[\mathrm{Fe}^{3+} \mathrm{Fe}^{3+}\right]^{*}$ & 11 & 9 \\
\hline$\left[\mathrm{Fe}^{3+} \mathrm{Fe}^{3+} / \mathrm{N}_{2} \mathrm{O}_{\mathrm{x}}\right]^{*}$ & 11 & 9 \\
\hline $\mathrm{TS}_{2}: \mathrm{N}_{2} \mathrm{O}$ activation & 9 & 9 \\
\hline$\left[\mathrm{Fe}^{4+} \mathrm{Fe}^{4+} \mathrm{O}_{\mathrm{x}} / \mathrm{N}_{2}\right]^{*}$ & & \\
\hline
\end{tabular}

\section{Section S7:}

Modeling of the reaction on the high spin and low spin potential energy surfaces

Figures S22-25 show the comparison of the reaction energetics for the conversion of methane to methanol on the high spin (HS) and low spin (LS) potential energy surfaces. Figures S24-S25 show bar plots comparing the reaction energies, forward activation energies, and reverse activation energies for each of the steps in the catalytic reaction. The clusters exhibit similar reactivity on the high spin and low spin states, with the largest difference in the $\mathrm{N}_{2} \mathrm{O}$ activation barrier of about $25 \mathrm{~kJ} / \mathrm{mol}$. Table S17 shows the RMSD and MAE values between the high spin and the low spin pathways for all reaction energies, forward activation energies, and reverse activation energies for each of the $\mathrm{O}_{b}$ and $\mathrm{O}_{t}$ pathways. 


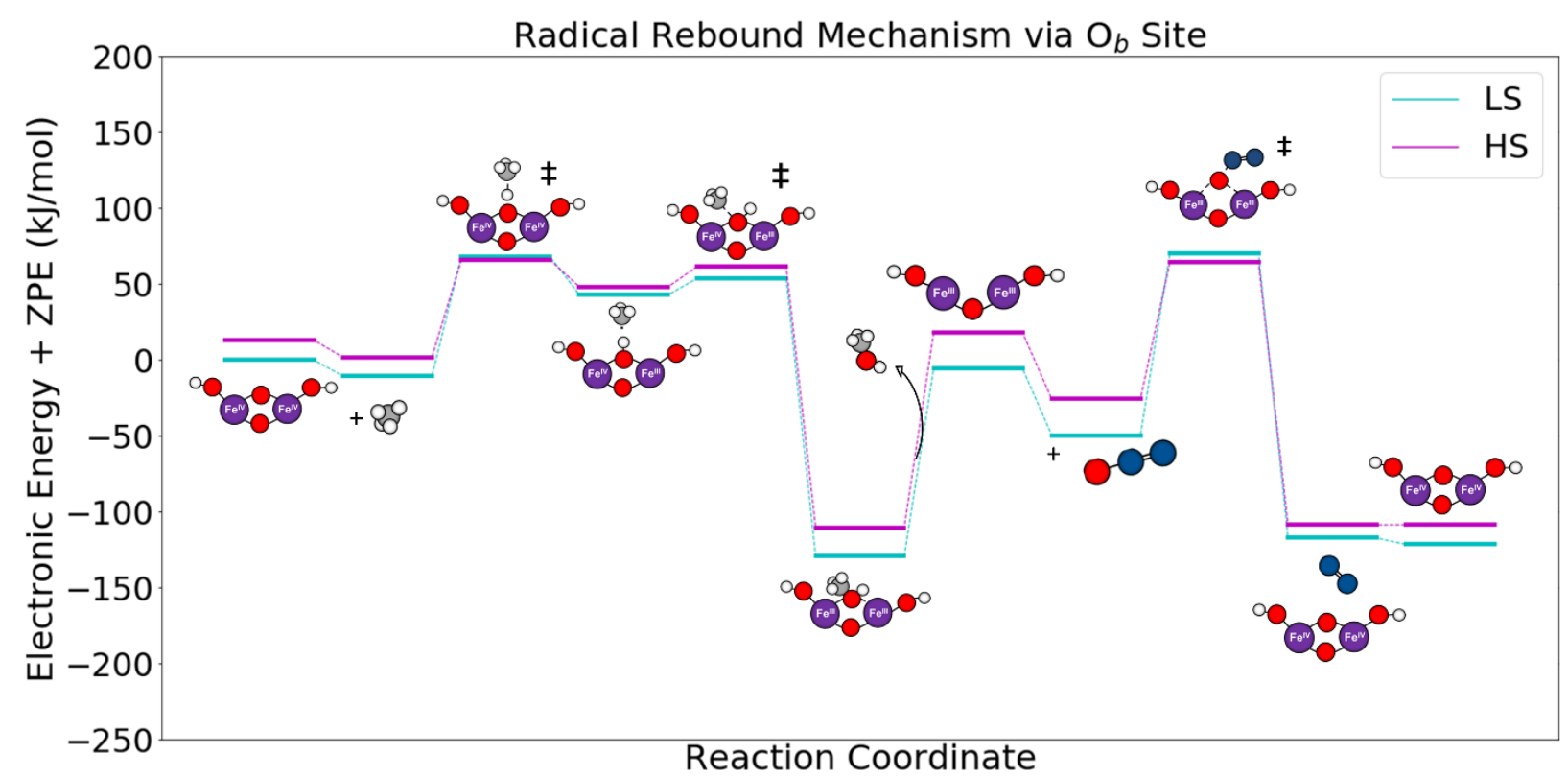

(a)

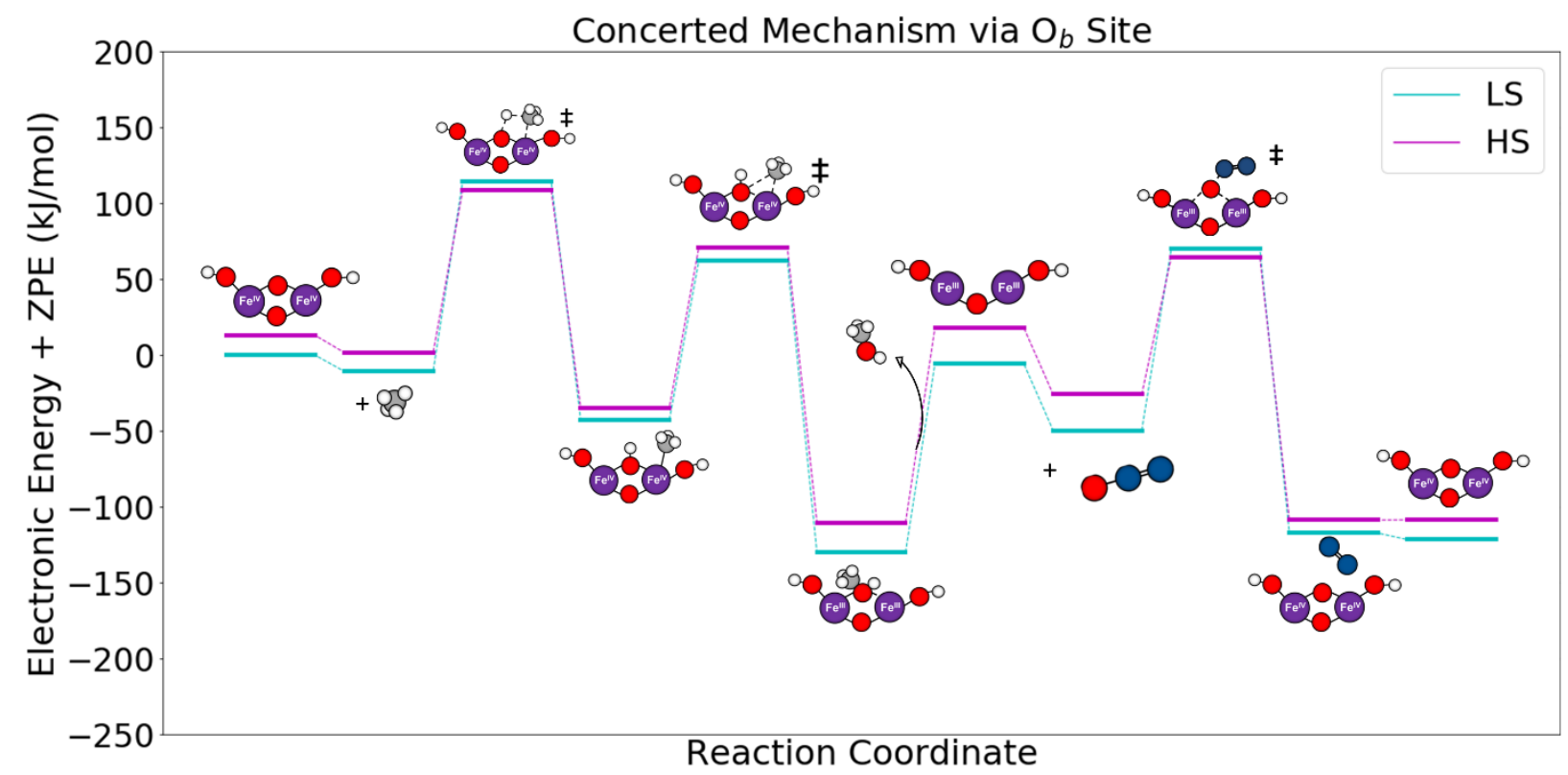

(b)

Figure S22: Comparison between the low spin and high spin states of the (a) radical rebound pathway and (b) concerted pathway via the $\mathrm{O}_{\mathrm{b}}$ site. The open-shell singlet is generally lower in energy. Energies for the low spin energy profiles were calcuted using the broken symmetry approach devised by Yamagushi. ${ }^{17}$ 


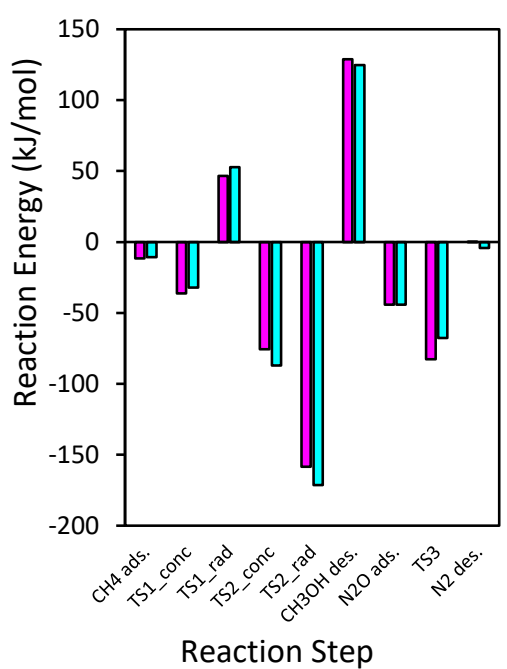

(a)

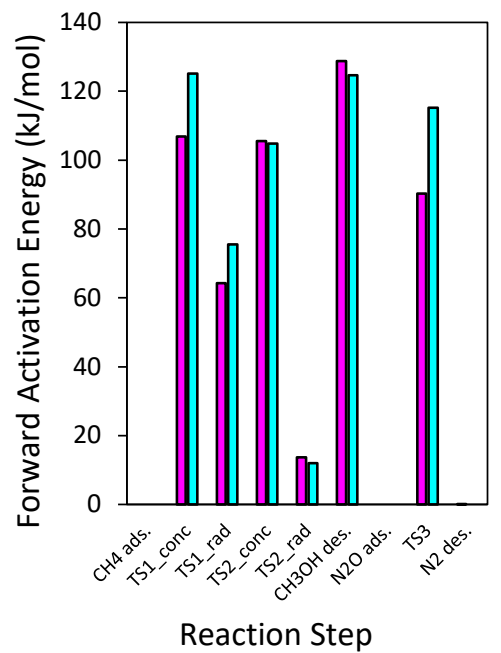

(b)

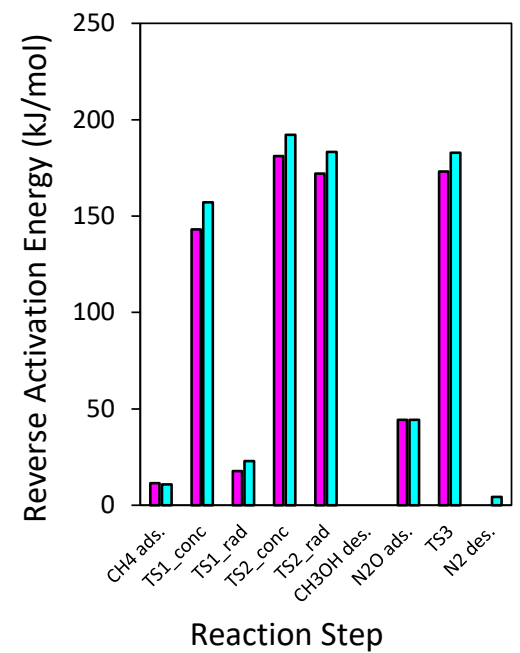

(c)

Figure S23: Barplots comparing (a) reaction energies, (b) forward activation energies, and (c) reverse activation energies on the high spin and low spin potential energy surfaces for the proposed reaction mechanisms occuring via the $\mathrm{O}_{\mathrm{b}}$ site. Magenta corresponds to the low spin energy pathway and light blue corresponds to the high spin energy pathway.

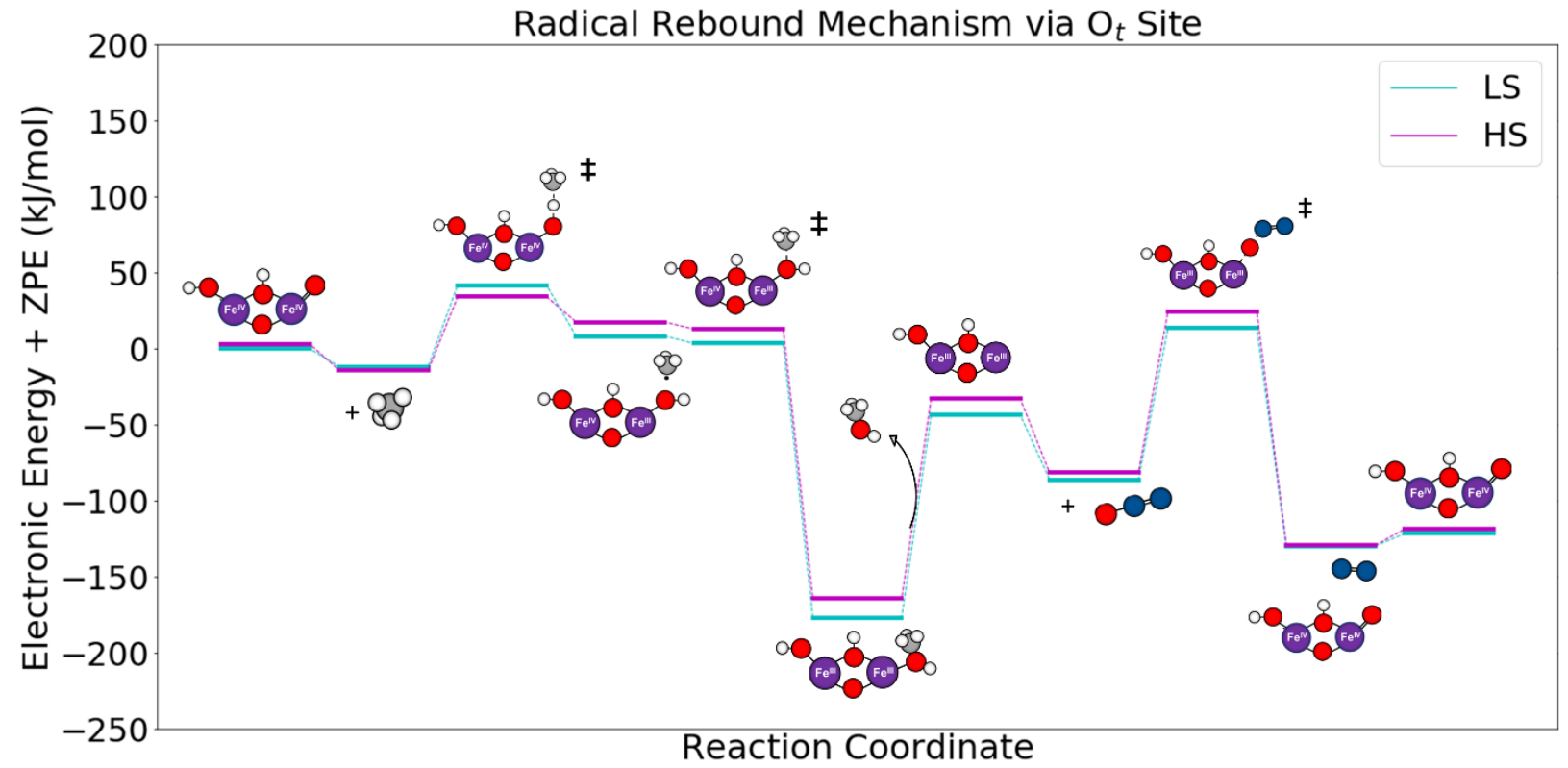

(a) 


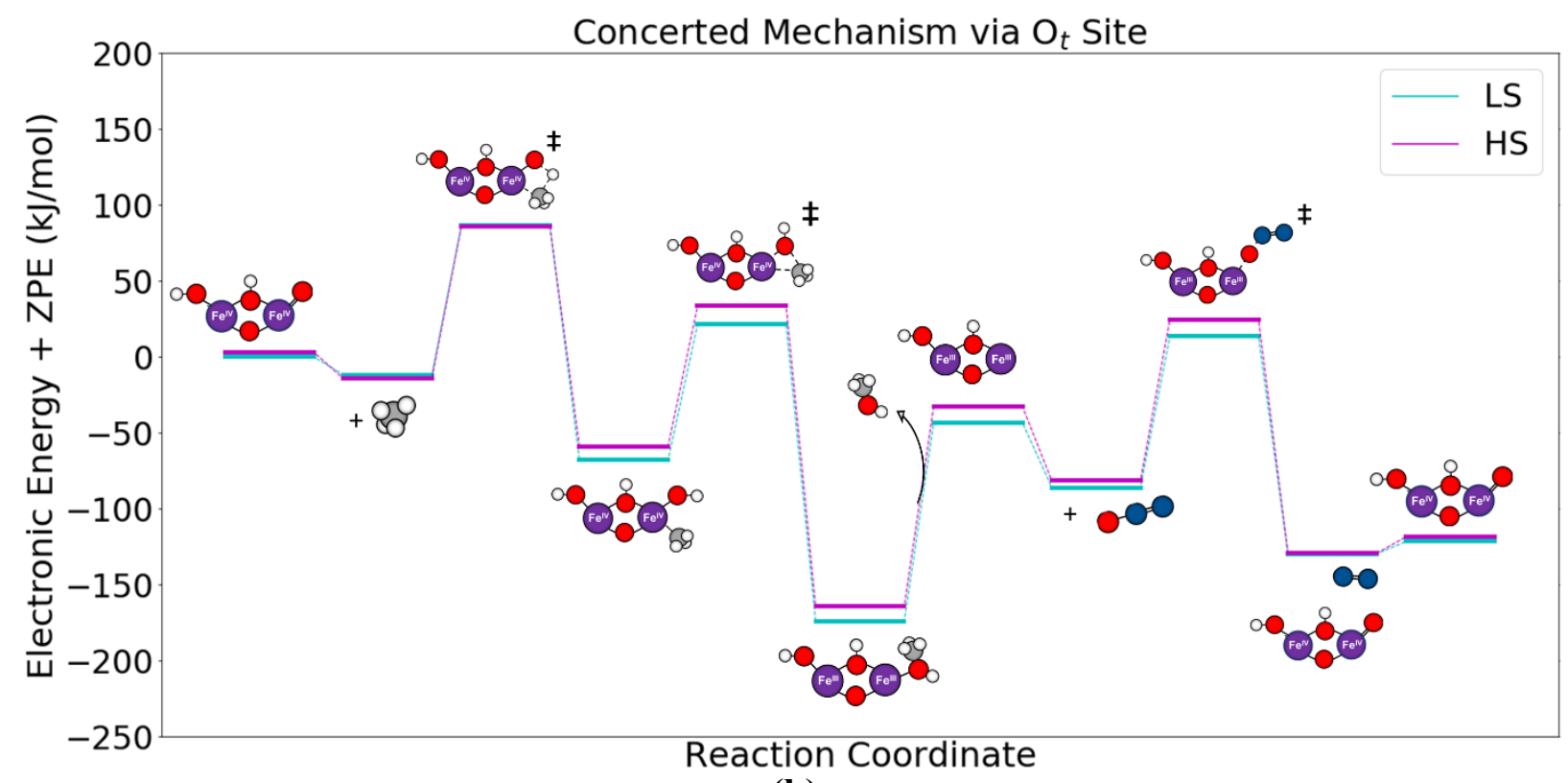

(b)

Figure S24: Comparison between the low spin and high spin states of the (a) radical rebound pathway and (b) concerted pathway via the $\mathrm{O}_{t}$ site. The open-shell singlet is generally lower in energy. Energies for the low spin energy profiles were calcuted using the broken symmetry approach devised by Yamagushi. ${ }^{17}$

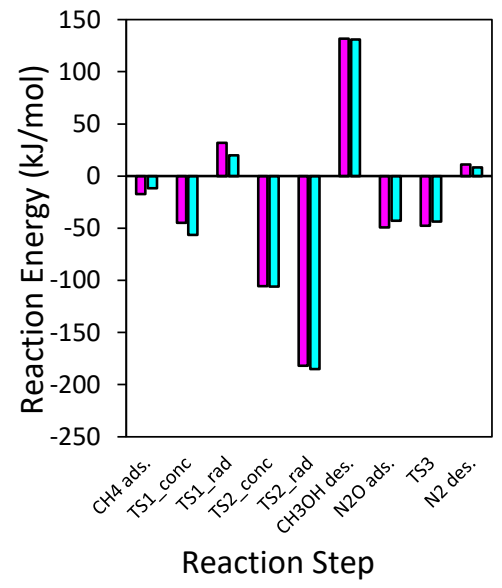

(a)

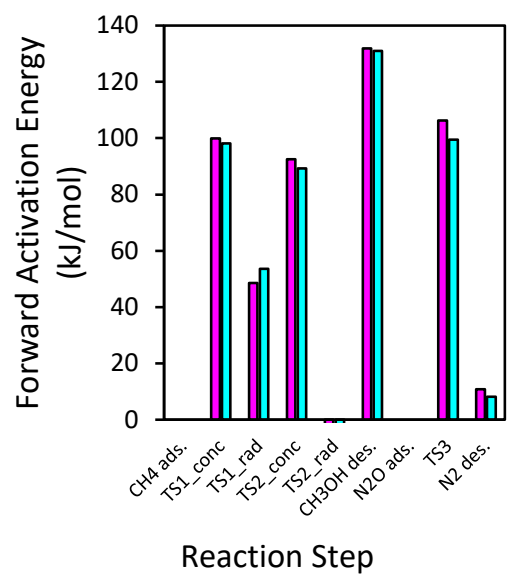

(b)

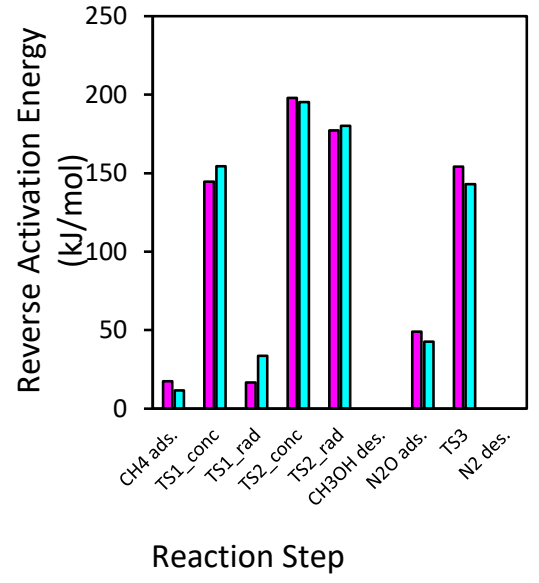

(c)

Figure S25: Barplots comparing (a) reaction energies, (b) forward activation energies, and (c) reverse activation energies on the high spin and low spin potential energy surfaces for the proposed reaction mechanisms occuring via the $\mathrm{O}_{\mathrm{t}}$ site. Magenta corresponds to the low spin energy pathway and light blue corresponds to the high spin energy pathway. 
Table S17: Root mean square deviation and mean average deviation of the high spin state pathway versus the low spin state pathway for all reaction energies, forward activation energies, and reverse activation energies.

\begin{tabular}{|c|c|c|}
\hline & RMSD & MAD \\
\hline Ob pathway & $9.78 \mathrm{~kJ} / \mathrm{mol}$ & $7.33 \mathrm{~kJ} / \mathrm{mol}$ \\
\hline Ot pathway & $6.79 \mathrm{~kJ} / \mathrm{mol}$ & $5.33 \mathrm{~kJ} / \mathrm{mol}$ \\
\hline
\end{tabular}

Table S18: $<\mathrm{S}^{2}>$ values for the most stable species in the proposed catalytic cycles. " $\mathrm{x}$ " can be "b" for bridging oxygen or " $\mathrm{t}$ " for terminal oxygen.

\begin{tabular}{|c|c|c|c|c|}
\hline & \multicolumn{2}{|c|}{$\left\langle\mathbf{S}^{2}\right\rangle$ value $\mathbf{L S}$} & \multicolumn{2}{|c|}{$\left\langle\mathbf{S}^{2}\right\rangle$ value $\mathrm{HS}$} \\
\hline & Ob pathway & Ot pathway & Ob pathway & Ot pathway \\
\hline$\left[\mathrm{Fe}^{4+} \mathrm{Fe}^{4+} \mathrm{O}_{\mathrm{x}}\right]$ & 4.0062 & 4.0912 & 20.1669 & 20.1761 \\
\hline$\left[\mathrm{Fe}^{4+} \mathrm{Fe}^{4+} \mathrm{O}_{\mathrm{x}} / \mathrm{CH}_{4}\right]^{*}$ & 4.0221 & 4.132 & 20.1663 & 20.1687 \\
\hline TS1 (radical-rebound) & 4.7396 & 4.7681 & 20.7655 & 20.7819 \\
\hline TS1 (concerted) & 4.075 & 4.1413 & 20.1784 & 20.1773 \\
\hline$\left[\mathrm{Fe}^{3+} \mathrm{Fe}^{4+}\left(\mathrm{O}_{\mathrm{x}}-\mathrm{H}\right) /{ }^{\circ} \mathrm{CH}_{3}\right]^{*}$ & 5.0129 & 4.1826 & 30.1161 & 30.1207 \\
\hline$\left[\mathrm{Fe}^{4+} \mathrm{Fe}^{4+}\left(\mathrm{O}_{\mathrm{x}}-\mathrm{H}\right)\left(\mathrm{CH}_{3}\right)\right]^{*}$ & 4.2213 & 4.1572 & 20.2944 & 20.2732 \\
\hline TS2 (radical-rebound) & 5.0424 & 4.9254 & 30.1124 & 30.1044 \\
\hline TS2 (concerted) & 4.9584 & 4.8782 & 30.0897 & 30.0761 \\
\hline$\left[\mathrm{Fe}^{3+} \mathrm{Fe}^{3+}\left(\mathrm{CH}_{3} \mathrm{O}_{\mathrm{x}} \mathrm{H}\right)\right]^{*}$ & 4.8378 & 4.8832 & 30.0254 & 30.0257 \\
\hline$\left[\mathrm{Fe}^{3+} \mathrm{Fe}^{3+}\right]^{*}$ & 4.8237 & 4.8507 & 30.0268 & 30.0286 \\
\hline$\left[\mathrm{Fe}^{3+} \mathrm{Fe}^{3+} / \mathrm{N}_{2} \mathrm{O}_{\mathrm{x}}\right]^{*}$ & 4.8155 & 4.9227 & 30.0262 & 30.0281 \\
\hline TS3: $\mathrm{N}_{2} \mathrm{O}$ activation & 4.898 & 4.7064 & 20.5547 & 20.7594 \\
\hline$\left[\mathrm{Fe}^{4+} \mathrm{Fe}^{4+} \mathrm{O}_{\times} / \mathrm{N}_{2}\right]^{*}$ & 4.0658 & 4.0927 & 20.1935 & 20.1763 \\
\hline
\end{tabular}

Table S19: Reaction energies and barriers for each of the steps in the catalytic cycles on the high spin potential energy surface

\begin{tabular}{|c|c|c|c|c|c|c|}
\hline \multirow[b]{2}{*}{ Step } & \multicolumn{3}{|c|}{ Ot pathway } & \multicolumn{3}{|c|}{ Ob pathway } \\
\hline & $\begin{array}{c}\text { Reaction } \\
\text { Energy }\end{array}$ & $\begin{array}{c}\text { Forward } \\
\text { Reaction } \\
\text { Activation } \\
\text { Energy }\end{array}$ & $\begin{array}{c}\text { Reverse } \\
\text { Reaction } \\
\text { Activation } \\
\text { Energy }\end{array}$ & $\begin{array}{c}\text { Reaction } \\
\text { Energy }\end{array}$ & $\begin{array}{c}\text { Forward } \\
\text { Reaction } \\
\text { Activation } \\
\text { Energy }\end{array}$ & $\begin{array}{c}\text { Reverse } \\
\text { Reaction } \\
\text { Activation } \\
\text { Energy }\end{array}$ \\
\hline 1 & -17.4 & 0 & 17.4 & -11.5 & 0 & 11.5 \\
\hline r2 & 31.8 & 48.5 & 16.7 & 46.5 & 64.3 & 17.8 \\
\hline r3 & -182 & -4.70 & 177 & -158 & 13.6 & 172 \\
\hline c2 & -44.7 & 100 & 145 & -36.3 & 107 & 143 \\
\hline c3 & -105 & 92.4 & 198 & -75.6 & 106 & 181 \\
\hline 4 & 132 & 132 & 0 & 129 & 129 & 0 \\
\hline 5 & -49.1 & 0 & 49.1 & -44.2 & 0 & 44.2 \\
\hline 6 & -47.8 & 106 & 154 & -82.7 & 90.3 & 173 \\
\hline 7 & 10.9 & 10.9 & 0 & 0.102 & 0.102 & 0 \\
\hline
\end{tabular}


Table S20: Reaction energies and barriers for each of the steps in the catalytic cycles on the low spin potential energy surface

\begin{tabular}{|c|c|c|c|c|c|c|}
\hline & \multicolumn{3}{|c|}{ Ot pathway } & \multicolumn{3}{c|}{ Ob pathway } \\
\cline { 2 - 7 } Step & $\begin{array}{c}\text { Reaction } \\
\text { Energy }\end{array}$ & $\begin{array}{c}\text { Forward } \\
\text { Reaction } \\
\text { Activation } \\
\text { Energy }\end{array}$ & $\begin{array}{c}\text { Reverse } \\
\text { Reaction } \\
\text { Activation } \\
\text { Energy }\end{array}$ & $\begin{array}{c}\text { Reaction } \\
\text { Energy } \\
\text { Reaction } \\
\text { Activation } \\
\text { Energy }\end{array}$ & $\begin{array}{c}\text { Reverse } \\
\text { Reaction } \\
\text { Activation } \\
\text { Energy }\end{array}$ \\
\hline $\mathbf{1}$ & -11.8 & 0 & 11.8 & -10.8 & 0 & 10.8 \\
$\mathbf{r 2}$ & 20.0 & 53.6 & 33.6 & 52.7 & 75.6 & 22.9 \\
$\mathbf{r 3}$ & -185 & -4.90 & 180 & -171 & 12.0 & 183.2 \\
$\mathbf{c 2}$ & -56.3 & 98.1 & 154 & -32.0 & 125 & 157 \\
$\mathbf{c 3}$ & -106 & 89.3 & 195 & -87.2 & 105 & 192 \\
$\mathbf{4}$ & 134 & 134 & 0 & 124.7 & 124.7 & 0 \\
$\mathbf{5}$ & -42.8 & 0 & 42.8 & -44.3 & 0 & 44.3 \\
$\mathbf{6}$ & -43.7 & 99.4 & 143 & -67.6 & 115 & 183 \\
$\mathbf{7}$ & 8.10 & 8.10 & 0 & -4.32 & 0 & 4.32 \\
\hline
\end{tabular}




\section{Section S8: Population Analysis}

\section{Spin density analysis for the low spin state of the $O_{b}$ pathway}

Table S21: NBO spin density values of $\mathrm{O}_{b}, \mathrm{Fe} 1, \mathrm{Fe} 2$, and $\mathrm{C}$ atoms of the catalytic species during the conversion of methane to methanol via a radical-rebound mechanism (open-shell singlet)

\begin{tabular}{|l|c|l|l|l|}
\hline \multicolumn{1}{|c|}{ Species } & $\mathbf{O}_{\mathrm{b}}$ & Fe1 & Fe2 & C \\
\hline$\left[\mathrm{Fe}^{4+} \mathbf{O}_{\mathrm{b}} \mathrm{Fe}^{4+} / \mathrm{CH}_{4}\right]^{*}$ & 0.02 & 3.10 & -3.14 & 0.02 \\
TS1 (radical pathway) & 0.36 & 3.19 & -3.84 & 0.54 \\
{$\left[\mathrm{Fe}^{4+}\left(\mathrm{O}_{\mathrm{b}}-\mathrm{H}\right) \mathrm{Fe}^{3+} / \cdot \mathrm{CH}_{3}\right]^{*}$} & 0.07 & 3.21 & -3.95 & 1.05 \\
$\mathrm{TS2}($ radical pathway) & -0.04 & 3.44 & -3.95 & 0.84 \\
{$\left[\mathrm{Fe}^{3+}\left(\mathrm{CH}_{3} \mathrm{O}_{\mathrm{b}} \mathrm{H}\right) \mathrm{Fe}^{3+}\right]^{*}$} & 0.00 & 3.90 & -3.89 & 0.00 \\
\hline
\end{tabular}

Table S22: NBO spin density values of $\mathrm{O}_{b}, \mathrm{Fe} 1, \mathrm{Fe} 2$, and $\mathrm{C}$ atoms of the catalytic species during the conversion of methane to methanol via a concerted mechanism (open-shell singlet)

\begin{tabular}{|l|c|c|c|c|}
\hline \multicolumn{1}{|c|}{ Species } & $\mathbf{O}_{\mathrm{b}}$ & $\mathrm{Fe} 1$ & $\mathrm{Fe} 2$ & $\mathrm{C}$ \\
\hline$\left[\mathrm{Fe}^{4+} \mathbf{O}_{\mathrm{b}} \mathrm{Fe}^{4+} / \mathrm{CH}_{4}\right]^{*}$ & 0.02 & 3.10 & -3.14 & 0.02 \\
$\mathrm{TS1}$ (concerted pathway) & -0.02 & 3.15 & -3.17 & -0.05 \\
{$\left[\mathrm{Fe}^{4+}\left(\mathrm{O}_{\mathrm{b}}-\mathrm{H}\right) \mathrm{Fe}^{3+}-\mathrm{CH}_{3}\right]$} & 0.04 & 3.44 & -3.26 & -0.28 \\
$\mathrm{TS2}($ concerted pathway) & 0.11 & 3.49 & -3.94 & 0.46 \\
{$\left[\mathrm{Fe}^{3+}\left(\mathrm{CH}_{3} \mathrm{O}_{\mathrm{b}} \mathrm{H}\right) \mathrm{Fe}^{3+}\right]^{*}$} & 0.00 & 3.90 & -3.89 & 0.00 \\
\hline
\end{tabular}

Table S23: NBO spin density values of $\mathrm{O}_{\mathrm{b}}, \mathrm{Fe} 1, \mathrm{Fe} 2$, and $\mathrm{N}$ atoms of the catalytic species during the $\mathrm{N}_{2} \mathrm{O}$ activation. (open-shell singlet)

\begin{tabular}{|l|c|c|c|c|}
\hline \multicolumn{1}{|c|}{ Species } & $\mathbf{O}_{\mathbf{b}}$ & Fe1 & Fe2 & $\mathbf{N}$ \\
\hline$\left[\mathrm{Fe}^{\mathbf{3 +}} \mathrm{Fe}^{\mathbf{3 +}} / \mathbf{N}_{\mathbf{2}} \mathbf{O}_{\mathbf{b}}\right]^{*}$ & 0.00 & 3.91 & -3.91 & 0.00 \\
TS3 $\left(\mathbf{N}_{\mathbf{2}} \mathbf{O}\right.$ activation) & -0.19 & 3.92 & -3.32 & -0.14 \\
{$\left[\mathrm{Fe}^{4+} \mathbf{O}_{\mathbf{b}} \mathrm{Fe}^{\mathbf{4 +}} / \mathbf{N}_{\mathbf{2}}\right]^{*}$} & -0.04 & 3.16 & -3.22 & 0.00 \\
\hline
\end{tabular}




\section{Spin density analysis for the high spin state of the $O_{t}$ pathway}

Table S24: NBO spin density values of $\mathrm{O}_{t}, \mathrm{Fe} 1, \mathrm{Fe} 2$, and $\mathrm{C}$ atoms of the catalytic species during the conversion of methane to methanol via a radical-rebound mechanism

\begin{tabular}{|l|c|c|c|c|}
\hline \multicolumn{1}{|c|}{ Species } & $\mathbf{O}_{\mathbf{t}}$ & Fe1 & Fe2 & C \\
\hline$\left[\mathrm{Fe}^{4+} \mathrm{Fe}^{4+} \mathbf{O}_{\mathrm{t}} / \mathrm{CH}_{4}\right]^{*}$ & 0.62 & 2.96 & 3.28 & 0.02 \\
TS1 (radical pathway) & -0.13 & 3.11 & 4.00 & -0.52 \\
{$\left[\mathrm{Fe}^{4+} \mathrm{Fe}^{3+}\left(\mathbf{O}_{\mathbf{t}}-\mathrm{H}\right) / \cdot \mathrm{CH}_{3}\right]^{*}$} & 0.23 & 3.28 & 4.00 & 1.06 \\
TS2 (radical pathway) & 0.02 & 3.59 & 3.99 & 0.64 \\
{$\left[\mathrm{Fe}^{3+} \mathrm{Fe}^{3+}\left(\mathrm{CH}_{3} \mathrm{O}_{\mathbf{t}} \mathrm{H}\right)\right]^{*}$} & 0.05 & 3.87 & 3.99 & 0.00 \\
\hline
\end{tabular}

Table S25: NBO spin density values of $\mathrm{O}_{\mathrm{t}}, \mathrm{Fe} 1, \mathrm{Fe} 2$, and $\mathrm{C}$ atoms of the catalytic species during the conversion of methane to methanol via a concerted mechanism

\begin{tabular}{|l|c|c|c|c|}
\hline \multicolumn{1}{|c|}{ Species } & $\mathbf{O}_{\mathrm{t}}$ & $\mathrm{Fe} 1$ & $\mathrm{Fe}$ & $\mathbf{C}$ \\
\hline$\left[\mathrm{Fe}^{4+} \mathrm{Fe}^{4+} \mathbf{O}_{\mathrm{t}} / \mathrm{CH}_{4}\right]^{*}$ & 0.62 & 2.96 & 3.28 & 0.02 \\
TS1 (concerted pathway) & 0.41 & 3.08 & 3.26 & 0.02 \\
{$\left[\mathrm{Fe}^{4+} \mathrm{Fe}^{4+}\left(\mathbf{O}_{\mathrm{t}}-\mathrm{H}\right)\left(\mathrm{CH}_{3}\right)\right]^{*}$} & 0.23 & 3.46 & 3.25 & -0.29 \\
$\mathrm{TS2}($ concerted pathway) & 0.34 & 3.46 & 3.99 & 0.29 \\
{$\left[\mathrm{Fe}^{3+} \mathrm{Fe}^{3+}\left(\mathrm{CH}_{3} \mathrm{O}_{\mathrm{t}} \mathrm{H}\right)\right]^{*}$} & 0.05 & 3.87 & 3.99 & 0.00 \\
\hline
\end{tabular}

Table S26: NBO spin density values of $\mathrm{O}_{\mathrm{t}}, \mathrm{Fe} 1, \mathrm{Fe} 2$, and $\mathrm{N}$ atoms of the catalytic species during the $\mathrm{N}_{2} \mathrm{O}$ activation.

\begin{tabular}{|l|c|c|c|c|}
\hline \multicolumn{1}{|c|}{ Species } & $\mathbf{O}_{\mathbf{t}}$ & Fe1 & Fe2 & $\mathbf{N}$ \\
\hline$\left[\mathrm{Fe}^{\mathbf{3 +}} \mathrm{Fe}^{\mathbf{3 +}} / \mathbf{N}_{\mathbf{2}} \mathbf{O}_{\mathrm{t}}\right]^{*}$ & 0.02 & 3.85 & 3.98 & 0.00 \\
$\mathrm{TS3}^{\mathbf{N}} \mathbf{N}_{\mathbf{2}} \mathbf{O}$ activation) & -0.04 & 3.91 & 3.26 & -0.19 \\
{$\left[\mathrm{Fe}^{4+} \mathrm{Fe}^{4+} \mathbf{O}_{\mathrm{t}} / \mathbf{N}_{\mathbf{2}}\right]^{*}$} & 0.56 & 3.06 & 3.30 & 0.00 \\
\hline
\end{tabular}

\section{Spin density analysis for the low spin state of $O_{t}$ pathway}

Table S27: NBO spin density values of $\mathrm{O}_{\mathrm{t}}, \mathrm{Fe} 1, \mathrm{Fe} 2$, and $\mathrm{C}$ atoms of the catalytic species during the conversion of methane to methanol via a radical-rebound mechanism (open-shell singlet)

\begin{tabular}{|l|c|l|l|c|}
\hline \multicolumn{1}{|c|}{ Species } & $\mathbf{O}_{\mathrm{t}}$ & $\mathrm{Fe} 1$ & $\mathrm{Fe} 2$ & $\mathrm{C}$ \\
\hline$\left[\mathrm{Fe}^{4+} \mathrm{Fe}^{4+} \mathrm{O}_{\mathrm{t}} / \mathrm{CH}_{4}\right]^{*}$ & 0.57 & 2.98 & -3.23 & 0.02 \\
$\mathrm{TS1}$ (radical pathway) & -0.05 & 3.86 & -3.20 & -0.53 \\
{$\left[\mathrm{Fe}^{4+} \mathrm{Fe}^{3+}\left(\mathrm{O}_{\mathrm{t}}-\mathrm{H}\right) / \mathrm{CH}_{3}\right]^{*}$} & 0.33 & 3.96 & -3.21 & -1.07 \\
$\mathrm{TS2}\left(\mathrm{radical}^{*}\right.$ pathway) & 0.17 & 3.26 & -3.96 & 1.04 \\
{$\left[\mathrm{Fe}^{3+} \mathrm{Fe}^{3+}\left(\mathrm{CH}_{3} \mathrm{O}_{\mathrm{t}} \mathrm{H}\right)\right]^{*}$} & 0.05 & 3.83 & -3.93 & 0.00 \\
\hline
\end{tabular}


Table S28: NBO spin density values of $\mathrm{O}_{\mathrm{t}}, \mathrm{Fe} 1, \mathrm{Fe} 2$, and $\mathrm{C}$ atoms of the catalytic species during the conversion of methane to methanol via a concerted mechanism (open-shell singlet)

\begin{tabular}{|l|c|l|l|c|}
\hline \multicolumn{1}{|c|}{ Species } & $\mathbf{O}_{\mathrm{t}}$ & $\mathrm{Fe} 1$ & $\mathrm{Fe} 2$ & $\mathrm{C}$ \\
\hline$\left[\mathrm{Fe}^{4+} \mathrm{Fe}^{4+} \mathrm{O}_{\mathrm{t}} / \mathrm{CH}_{4}\right]^{*}$ & 0.57 & 2.98 & -3.23 & 0.02 \\
TS1 (concerted pathway) & 0.36 & 3.08 & -3.23 & 0.01 \\
{$\left[\mathrm{Fe}^{4+} \mathrm{Fe}^{4+}\left(\mathrm{O}_{\mathrm{t}}-\mathrm{H}\right)\left(\mathrm{CH}_{3}\right)\right]^{*}$} & 0.21 & 3.42 & -3.20 & -0.27 \\
$\mathrm{TS2}($ concerted pathway) & 0.34 & 3.40 & -3.91 & 0.25 \\
{$\left[\mathrm{Fe}^{3+} \mathrm{Fe}^{3+}\left(\mathrm{CH}_{3} \mathrm{O}_{\mathrm{t}} \mathrm{H}\right)\right]^{*}$} & 0.05 & 3.83 & -3.93 & 0.00 \\
\hline
\end{tabular}

Table S29: NBO spin density values of $\mathrm{O}_{\mathrm{t}}, \mathrm{Fe} 1, \mathrm{Fe} 2$, and $\mathrm{N}$ atoms of the catalytic species during the $\mathrm{N}_{2} \mathrm{O}$ activation. (open-shell singlet)

\begin{tabular}{|c|c|c|c|c|}
\hline Species & $\mathbf{O}_{t}$ & Fe1 & Fe2 & $\mathbf{N}$ \\
\hline$\left[\mathrm{Fe}^{3+} \mathrm{Fe}^{3+} / \mathrm{N}_{2} \mathrm{O}_{\mathrm{t}}\right]^{*}$ & 0.02 & 3.81 & -3.92 & 0.00 \\
\hline TS3 ( $\mathrm{N}_{2} \mathrm{O}$ activation) & -0.07 & 3.86 & -3.30 & -0.18 \\
\hline$\left[\mathrm{Fe}^{4+} \mathrm{Fe}^{4+} \mathrm{O}_{\mathrm{t}} / \mathrm{N}_{2}\right]^{*}$ & 0.50 & 3.07 & -3.23 & 0.00 \\
\hline
\end{tabular}

\section{Section S9}

\section{Molecular orbital analysis}

\section{Molecular orbital decomposition analysis for the high spin case of $O_{b}$ and $O_{t}$ pathways}

Table S30: MO energies and percent orbital composition of the two highest HOMOs and two lowest LUMOs for (a) $\left[\mathrm{Fe}^{4+} \mathrm{O}_{\mathrm{b}} \mathrm{Fe}^{4+}\right]$ and (b) $\left[\mathrm{Fe}^{3+} \mathrm{Fe}^{3+}\right]_{\mathrm{b}}$.

\section{Oxidized Cluster with $\mathrm{O}_{\mathrm{b}}$ site}

\begin{tabular}{|c|l|c|c|c|c|}
\hline \multicolumn{2}{|c|}{} & HOMO - 1 & HOMO & LUMO & LUMO + 1 \\
\hline \multicolumn{2}{|c|}{ Orbital Energy } & -7.36 & -6.96 & -5.65 & -5.48 \\
\hline \multirow{2}{*}{ Orbital Fractional } & $\mathbf{O}_{\mathbf{b}}$ p orbitals & 12.03 & 41.43 & 6.15 & 12.83 \\
Contributions & Fe1 d orbitals & 13.90 & 14.60 & 16.53 & 18.23 \\
& Fe2 d orbitals & 12.84 & 14.83 & 16.71 & 18.12 \\
\hline
\end{tabular}

(a)

Reduced Cluster with $\mathrm{O}_{\mathrm{b}}$ vacancy

\begin{tabular}{|c|l|c|c|c|c|}
\hline \multicolumn{2}{|c|}{} & HOMO - 1 & HOMO & LUMO & LUMO + 1 \\
\hline \multicolumn{2}{|c|}{ Orbital Energy } & -6.46 & -6.18 & -5.14 & -5.12 \\
\hline \multirow{2}{*}{ Orbital Fractional } & $\mathbf{O}_{\mathrm{b}}$ p orbitals & 0.00 & 0.00 & 0.00 & 0.00 \\
Contributions & Fe1 d orbitals & 11.15 & 16.04 & 44.05 & 40.19 \\
& Fe2 d orbitals & 13.41 & 13.87 & 44.62 & 46.02 \\
\hline
\end{tabular}

(b) 
Table S31: MO energies and percent orbital composition of the two highest HOMOs and two lowest LUMOs for (a) $\left[\mathrm{Fe}^{4+} \mathrm{Fe}^{4+} \mathrm{O}_{\mathrm{t}}\right]$ and (b) $\left[\mathrm{Fe}^{3+} \mathrm{Fe}^{3+}\right]_{\mathrm{t}}$.

Oxidized Cluster with $\mathrm{O}_{\mathrm{t}}$ site

\begin{tabular}{|c|l|c|c|c|c|}
\hline \multicolumn{2}{|c|}{} & HOMO - 1 & HOMO & LUMO & LUMO + 1 \\
\hline \multicolumn{2}{|c|}{ Orbital Energy } & -6.86 & -6.41 & -5.84 & -5.48 \\
\hline \multirow{2}{*}{ Orbital Fractional } & $\mathbf{O}_{\mathbf{t}}$ p orbitals & 50.87 & 37.23 & 1.25 & 1.30 \\
Contributions & Fe1 d orbitals & 28.50 & 29.81 & 1.29 & 1.82 \\
& Fe2 d orbitals & 1.16 & 0.89 & 30.64 & 75.86 \\
\hline
\end{tabular}

(a)

Reduced Cluster with $\mathrm{O}_{\mathrm{t}}$ vacancy

\begin{tabular}{|c|l|c|c|c|c|}
\hline \multicolumn{2}{|c|}{} & HOMO - 1 & HOMO & LUMO & LUMO + 1 \\
\hline \multicolumn{2}{|c|}{ Orbital Energy } & -6.32 & -6.03 & -5.38 & -4.72 \\
\hline \multirow{2}{*}{ Orbital Fractional } & $\mathbf{O}_{\mathbf{t}} \mathbf{p}$ orbitals & 0.00 & 0.00 & 0.00 & 0.00 \\
Contributions & Fe1 d orbitals & 21.75 & 0.64 & 61.11 & 65.56 \\
& Fe2 d orbitals & 3.78 & 24.84 & 1.12 & 5.19 \\
\hline
\end{tabular}

(b)

Molecular orbital decomposition analysis for the low spin case of $O_{b}$ and $O_{t}$ pathways

Table S32: MO energies and percent orbital composition of the two highest HOMOs and two lowest LUMOs for (a) $\left[\mathrm{Fe}^{4+} \mathrm{O}_{\mathrm{b}} \mathrm{Fe}^{4+}\right]$ and (b) $\left[\mathrm{Fe}^{3+} \mathrm{Fe}^{3+}\right]_{\mathrm{b}}$.

Oxidized Cluster with $\mathrm{O}_{\mathrm{b}}$ site

\begin{tabular}{|c|l|c|c|c|c|}
\hline \multicolumn{2}{|c|}{} & HOMO - 1 & HOMO & LUMO & LUMO + 1 \\
\hline \multicolumn{2}{|c|}{ Orbital Energy } & -7.15 & -7.14 & -5.68 & -5.68 \\
\hline \multirow{2}{*}{ Orbital Fractional } & $\mathbf{O}_{\mathrm{b}}$ p orbitals & 1.16 & 1.16 & 12.78 & 12.78 \\
Contributions & Fe1 d orbitals & 28.58 & 28.58 & 35.60 & 35.60 \\
& Fe2 d orbitals & 49.86 & 49.86 & 36.30 & 36.30 \\
\hline
\end{tabular}

(a)

Reduced Cluster with $\mathrm{O}_{\mathrm{b}}$ vacancy

\begin{tabular}{|c|l|c|c|c|c|}
\hline \multicolumn{2}{|c|}{} & HOMO - 1 & HOMO & LUMO & LUMO + 1 \\
\hline \multicolumn{2}{|c|}{ Orbital Energy } & -6.43 & -6.41 & -4.86 & -4.85 \\
\hline \multirow{2}{*}{ Orbital Fractional } & $\mathbf{O}_{\mathbf{b}} \mathbf{p}$ orbitals & 0.00 & 0.00 & 0.00 & 0.00 \\
Contributions & Fe1 d orbitals & 70.86 & 70.86 & 9.08 & 9.08 \\
& Fe2 d orbitals & 8.82 & 8.82 & 71.72 & 71.72 \\
\hline
\end{tabular}

(b) 
Table S33: MO energies and percent orbital composition of the two highest HOMOs and two lowest LUMOs for (a) $\left[\mathrm{Fe}^{4+} \mathrm{Fe}^{4+} \mathrm{O}_{\mathrm{t}}\right]$ and (b) $\left[\mathrm{Fe}^{3+} \mathrm{Fe}^{3+}\right]_{\mathrm{t}}$.

Oxidized Cluster with $\mathrm{O}_{\mathrm{t}}$ site

\begin{tabular}{|c|l|c|c|c|c|}
\hline \multicolumn{2}{|c|}{} & HOMO - 1 & HOMO & LUMO & LUMO + 1 \\
\hline \multicolumn{2}{|c|}{ Orbital Energy } & -6.84 & -6.42 & -5.87 & -5.46 \\
\hline \multirow{2}{*}{ Orbital Fractional } & $\mathbf{O}_{\mathbf{t}}$ p orbitals & 0.77 & 2.15 & 4.07 & 4.07 \\
Contributions & Fe1 d orbitals & 35.39 & 32.36 & 42.66 & 42.66 \\
& Fe2 d orbitals & 43.91 & 47.56 & 32.16 & 32.16 \\
\hline
\end{tabular}

(a)

\begin{tabular}{|}
\begin{tabular}{|c|l|c|c|c|c|}
\hline \multicolumn{2}{|c|}{ Reduced Cluster with $\mathbf{~}_{\mathbf{t}}$ vacancy } \\
\hline \multicolumn{2}{|c|}{ Orbital Energy } & HOMO - 1 & HOMO & LUMO & LUMO + 1 \\
\hline \multirow{2}{*}{ Orbital Fractional } & $\mathbf{O}_{\mathbf{t}}$ p orbitals & -6.37 & -6.01 & -5.18 & -4.60 \\
\hline Contributions & Fe1 d orbitals & 0.00 & 0.00 & 0.00 & 0.00 \\
& Fe2 d orbitals & 18.87 & 18.87 & 21.23 & 9.37 \\
& 66.09 & 66.09 & 61.03 & 62.24 \\
\hline
\end{tabular}
\end{tabular}

(b)

\section{Section S10}

\section{Species DFT energies}

Table S34: DFT Electronic energies for the all species in reaction pathways at the M06-L level of theory.

\begin{tabular}{|c|c|c|c|c|c|}
\hline & \multicolumn{3}{|c|}{ Ob pathway } & \multicolumn{2}{c|}{ Ot pathway } \\
\hline & LS & HS & $\begin{array}{l}\text { On Porphyrin } \\
\text { Support }(\text { HS })\end{array}$ & LS & HS \\
\hline$\left[\mathrm{Fe}^{4+} \mathrm{Fe}^{4+} \mathrm{O}_{\mathrm{x}}\right]$ & -3298.0265 & -3298.0226 & -6204.7554 & -3298.0136 & -3298.0129 \\
\hline$\left[\mathrm{Fe}^{4+} \mathrm{Fe}^{4+} \mathrm{O}_{\mathrm{x}} / \mathrm{CH}_{4}\right]^{*}$ & -3338.5096 & -3338.5059 & -6245.2399 & -3338.4977 & -3338.4986 \\
\hline $\mathrm{TS} 1$ (radical-rebound) & -3338.4720 & -3338.4726 & -6245.2046 & -3338.4681 & -3338.4719 \\
\hline $\mathrm{TS} 1($ concerted) & -3338.4588 & -3338.4607 & -6245.1927 & -3338.4558 & -3338.4561 \\
\hline$\left[\mathrm{Fe}^{3+} \mathrm{Fe}^{4+}\left(\mathrm{O}_{\mathrm{x}} \mathrm{H}\right){ }^{\bullet} \mathrm{CH}_{3}\right]^{*}$ & -3338.4838 & -3338.4819 & -6245.2151 & -3338.4837 & -3338.4810 \\
\hline$\left[\mathrm{Fe}^{4+} \mathrm{Fe}^{4+}\left(\mathrm{O}_{\mathrm{x}}-\mathrm{H}\right)\left(\mathrm{CH}_{3}\right)\right]^{*}$ & -3338.5204 & -3338.5181 & -6245.2484 & -3338.5174 & -3338.5147 \\
\hline $\mathrm{TS} 2\left(\mathrm{radical}_{-} \mathrm{rebound}\right)$ & -3338.4803 & -3338.4781 & -6245.2104 & -3338.4873 & -3338.4843 \\
\hline $\mathrm{TS} 2(\mathrm{concerted})$ & -3338.4790 & -3338.4763 & -6245.2089 & -3338.4821 & -3338.4783 \\
\hline$\left[\mathrm{Fe}^{3+} \mathrm{Fe}^{3+}\left(\mathrm{CH} \mathrm{O}_{\mathrm{x}} \mathrm{H}\right)\right]^{*}$ & -3338.5575 & -3338.5516 & -6245.2882 & -3338.5634 & -3338.5592 \\
\hline$\left[\mathrm{Fe}^{3+} \mathrm{Fe}^{3+}\right]^{*}$ & -3222.8944 & -3222.8870 & -6129.6292 & -3222.8969 & -3222.8936 \\
\hline$\left[\mathrm{Fe}^{3+} \mathrm{Fe}^{3+} / \mathrm{N}_{2} \mathrm{O}_{\mathrm{x}}\right]^{*}$ & -3407.4284 & -3407.4210 & -6314.1617 & -3407.4300 & -3407.4290 \\
\hline $\mathrm{TS} 3: \mathrm{N}_{2} \mathrm{O}$ activation & -3407.3808 & -3407.3831 & -6314.1149 & -3407.3878 & -3407.3846 \\
\hline$\left[\mathrm{Fe}^{4+} \mathrm{Fe}^{4+} \mathrm{O}_{\mathrm{x}} / \mathrm{N}_{2}\right]^{*}$ & -3407.4519 & -3407.4496 & -6314.125 & -3407.4454 & -3407.4454 \\
\hline
\end{tabular}




\section{Section S11}

\section{Full Gaussian Citation}

M. J. Frisch, G. W. Trucks, H. B. Schlegel, G. E. Scuseria, M. A. Robb, J. R. Cheeseman, G. Scalmani, V. Barone, B. Mennucci, G. A. Petersson, H. Nakatsuji, M. Caricato, X. Li, H. P. Hratchian, A. F. Izmaylov, J. Bloino, G. Zheng, J. L. Sonnenberg, M. Hada, M. Ehara, K. Toyota, R. Fukuda, J. Hasegawa, M. Ishida, T. Nakajima, Y. Honda, O. Kitao, H. Nakai, T. Vreven, J. A. Montgomery, Jr., J. E. Peralta, F. Ogliaro, M. Bearpark, J. J. Heyd, E. Brothers, K. N. Kudin, V. N. Staroverov, R. Kobayashi, J. Normand, K. Raghavachari, A. Rendell, J. C. Burant, S. S. Iyengar, J. Tomasi, M. Cossi, N. Rega, J. M. Millam, M. Klene, J. E. Knox, J. B. Cross, V. Bakken, C. Adamo, J. Jaramillo, R. Gomperts, R. E. Stratmann, O. Yazyev, A. J. Austin, R. Cammi, C. Pomelli, J. W. Ochterski, R. L. Martin, K. Morokuma, V. G. Zakrzewski, G. A. Voth, P. Salvador, J. J. Dannenberg, S. Dapprich, A. D. Daniels, Ö. Farkas, J. B. Foresman, J. V. Ortiz, J. Cioslowski, and D. J. Fox, Gaussian 09 (Gaussian, Inc., Wallingford CT, 2009).

\section{References}

1. Feng, D. W.; Gu, Z. Y.; Li, J. R.; Jiang, H. L.; Wei, Z. W.; Zhou, H. C., ZirconiumMetalloporphyrin PCN-222: Mesoporous Metal-Organic Frameworks with Ultrahigh Stability as Biomimetic Catalysts. Angew. Chem. Int. Edit. 2012, 51, 10307-10310.

2. Doan, H. A.; Li, Z. Y.; Farha, O. K.; Hupp, J. T.; Snurr, R. Q., Theoretical Insights Into Direct Methane to Methanol Conversion Over Supported Dicopper Oxo Nanoclusters. Catal. Today 2018, 312, 2-9.

3. Huang, S. P.; Shiota, Y.; Yoshizawa, K., DFT Study of the Mechanism for Methane Hydroxylation by Soluble Methane Monooxygenase (sMMO): Effects of Oxidation State, Spin State, and Coordination Number. Dalton T. 2013, 42, 1011-1023.

4. Cohen, A. J.; Tozer, D. J.; Handy, N. C., Evaluation of $\left\langle\mathrm{S}^{2}\right\rangle$ in Density Functional Theory. $J$. Chem. Phys. 2007, 126, 214104.

5. Wang, J. H.; Becke, A. D.; Smith, V. H., Evaluation of $\left\langle\mathrm{S}^{2}\right\rangle$ in Restricted, Unrestricted HartreeFock, and Density-Functional Based Theories. J. Chem. Phys. 1995, 102, 3477-3480.

6. Grafenstein, J.; Cremer, D., On the Diagnostic Value of $\left\langle\mathrm{S}^{2}\right\rangle$ in Kohn-Sham Density Functional Theory. Mol. Phys. 2001, 99, 981-989.

7. Cramer, C. J., Essentials of computational chemistry : theories and models. 2nd ed.. ed.; Wiley: Chichester, West Sussex, England Hoboken, NJ, 2004.

8. Gaggioli, C. A.; Stoneburner, S. J.; Cramer, C. J.; Gagliardi, L., Beyond Density Functional Theory: The Multiconfigurational Approach To Model Heterogeneous Catalysis. ACS Catal. 2019, 9, 8481-8502.

9. Roos, B. O.; Taylor, P. R.; Siegbahn, P. E. M., A Complete Active Space SCF Method (CASSCF) Using a Density-Matrix Formulated Super-CI Approach. Chem. Phys. 1980, 48, 157173.

10. Malmqvist, P. A.; Pierloot, K.; Shahi, A. R. M.; Cramer, C. J.; Gagliardi, L., The Restricted Active Space Followed by Second-Order Perturbation Theory Method: Theory and Application to the Study of $\mathrm{CuO}_{2}$ and $\mathrm{Cu}_{2} \mathrm{O}_{2}$ systems. J. Chem. Phys. 2008, 128, 204109. 
11. Malmqvist, P. A.; Rendell, A.; Roos, B. O., The Restricted Active Space Self-Consistent-Field Method, Implemented with a Split Graph Unitary Group Approach. J. Phys. Chem. 1990, 94, 5477-5482.

12. Andersson, K.; Malmqvist, P. A.; Roos, B. O., 2nd-Order Perturbation-Theory with a Complete Active Space Self-Consistent Field Reference Function. J. Chem. Phys. 1992, 96, 1218-1226.

13. Sauri, V.; Serrano-Andres, L.; Shahi, A. R. M.; Gagliardi, L.; Vancoillie, S.; Pierloot, K., Multiconfigurational Second-Order Perturbation Theory Restricted Active Space (RASPT2) Method for Electronic Excited States: A Benchmark Study. J. Chem. Theory Comput. 2011, 7, 153-168.

14. Aquilante, F.; De Vico, L.; Ferre, N.; Ghigo, G.; Malmqvist, P. A.; Neogrady, P.; Pedersen, T. B.; Pitonak, M.; Reiher, M.; Roos, B. O.; Serrano-Andres, L.; Urban, M.; Veryazov, V.; Lindh, R., Software News and Update MOLCAS 7: The Next Generation. J. Comput. Chem. 2010, 31, 224-247.

15. Roos, B. O.; Lindh, R.; Malmqvist, P. A.; Veryazov, V.; Widmark, P. O., Main Group Atoms and Dimers Studied with a New Relativistic ANO Basis Set. J. Phys. Chem. A 2004, 108, 28512858.

16. Roos, B. O.; Lindh, R.; Malmqvist, P. A.; Veryazov, V.; Widmark, P. O., New Relativistic ANO Basis Sets for Transition Metal Atoms. J. Phys. Chem. A 2005, 109, 6575-6579.

17. Yamaguchi, K.; Fukui, H.; Fueno, T., Molecular-Orbital (MO) Theory for Magnetically Interacting Organic-Compounds - Ab initio MO Calculations of the Effective Exchange Integrals for Cyclophane-Type Carbene Dimers. Chem. Lett. 1986, 625-628. 